\title{
Synthesis and characterization of novel phosphate glass matrix nanocomposites containing polyhedral oligomeric silsesquioxane with improved properties
}

\author{
Kyoungtae Kimª, Todd M. Alam ${ }^{\mathrm{b}}$, Joseph D. Lichtenhan ${ }^{\mathrm{c}}$, Joshua U. Otaigbe ${ }^{\mathrm{a}^{*}}$ \\ a School of Polymers and High Performance Materials, the University of Southern Mississippi, \\ 118 College Drive, Hattiesburg, Mississippi, 39406 \\ ${ }^{\mathrm{b}}$ Department of Organic Materials Science, Sandia National Laboratories, Albuquerque, New \\ Mexico 87185 \\ ${ }^{c}$ Hybrid Plastics, 55 W.L. Runnels Industrial Drive, Hattiesburg, MS 39401 \\ * Corresponding Author: Email address: Joshua.otaigbe@usm.edu \\ Phone: (601) 266-5596, Fax: (601) 266-5504
}

Submitted to Journal of Non-Crystalline Solids, January 20, 2017

(C) 2017. This manuscript version is made available under the Elsevier user license http://www.elsevier.com/open-access/userlicense/1.0/ 


\begin{abstract}
The preparation and characterization of novel tin fluorophosphate glass (Pglass) matrix nanocomposite materials containing nanoscale trisilanolphenyl polyhedral oligomeric silsesquioxane (POSS) prepared via classical glass synthesis was investigated to accelerate efforts to develop novel hybrid Pglass/POSS nanocomposites with enhanced benefits in suitable diverse applications. The glass transition temperatures $\left(T_{g}\right)$ of the obtained nanocomposites ranged from $121.6^{\circ}$ to $147.6^{\circ} \mathrm{C}$ to an extent that depends on the nano-POSS concentrations ( $\leq$ 10 wt.\% POSS) in the nanocomposites. The obtained scanning electron microscopy with energy-dispersive $\mathrm{x}$-ray spectroscopy and atomic force microscopy results confirmed the homogeneous molecular level dispersion of the POSS cages in the continuous Pglass matrix of the nanocomposite. Chemical reaction (or bonding) between the constituents of the nanocomposites was confirmed by Fourier transform infrared spectroscopy, X-ray photoelectron spectroscopy, and nuclear magnetic resonance spectroscopy. The rheological (storage and loss modulus) and nanomechanical (elastic modulus) properties of the nanocomposites significantly improved with increasing nano-POSS concentrations up to $10 \mathrm{wt} \%$ POSS. The molecular dispersion of the POSS and its strong physicochemical interaction with the continuous Pglass matrix can be tailored to satisfy requirements of a number of optomechanical applications where the pure glass is not useable.
\end{abstract}

Keywords: Tin fluorophosphate glass, Polyhedral oligomeric silsesquioxane, Melt rheology, Nanomechanical properties, Glass matrix nanocomposites, Molecular silica 


\section{Introduction}

Due to their design flexibility, improved performance properties, and relative ease of processing, nanocomposites composed of a continuous polymer matrix incorporating inorganic fillers such as exfoliated layered silicates, alumina, carbon fibers, carbon nanotubes and borosilicate glasses have spurred significant academic and industrial research interests in exploring feasibility of their uses in a wide range of diverse application areas like automotive, aerospace, and packing applications [1-9]. In general, composites materials can be prepared by physical mixing [9] or chemical (sol-gel) reactions [10] between the composite matrix and filler materials as previously reported in the literature.

Nanocomposites can be defined as matrix materials (e.g. glass-ceramics and polymers) that are chemically or physically combined with relatively small concentrations of nanofillers (e.g., carbon nanotubes, graphene, exfoliated layered silicates) to produce materials with improved mechanical and melt rheological properties. Nanocomposites include hybrid composite materials in which at least one of the phases has nanometer length scale dimensions that facilitate significant improvement of the limited properties of the continuous matrix materials in the nanocomposites. The reported enhanced nanoscale size effects in nanocomposites avoid the disadvantages and limitations of traditional microcomposites [11, 12]. It is worthy to note that as the size of the nanofiller decreases, the interaction between the nanoscale dispersed fillers and the continuous matrix materials in the nanocomposite increase significantly, and in turn, leads to mechanical and melt rheological properties by several orders of magnitude. The molecular size similarity between the nanofiller and matrix materials and the relative increased surface area allows efficient control of morphology and physical properties such as chain motion and glass transition temperature $\left(T_{g}\right)$ of the nanocomposites materials.

In traditional polymer matrix composites, glass and carbon fibers with micrometer length scales are widely used as fillers to improve thermal, mechanical and chemical resistant properties of the continuous polymer matrices in the composites. Recently, phosphate glasses (Pglass) have been investigated as filler materials in polymer matrices $[9,13-18]$ because they have unique properties of low- $T_{g}$ and excellent desirable properties like chemical durability, intrinsic flame resistance, higher thermal expansion, optical clarity, non-toxic, low process temperature and biocompatibility [19-23]. In the current study, inorganic phosphate glass is used as the continuous matrix to yield optomechanical phosphate glass matrix nanocomposites that are somewhat similar to glass-ceramic matrix nanocomposites reinforced with nanofillers such as carbon nanotubes and nanosized $\mathrm{SiC}$ with improved mechanical properties reported in 
the literature [24-29]. Note that the current Pglass matrix nanocomposites are made via a one pot synthesis method at remarkably lower temperatures than that used for making glassceramics and borosilicate matrix matric microcomposites already mentioned.

In contrast to the current study, other researchers have reported incorporation of ceramic fillers in the form of addition of carbon or silicon carbide particles or fibers into borosilicate glass matrices to produce glass matrix composites with improvements in performance in applications such as structural components for high temperature and impact resistant panels, which in itself is noncompliant as a result of elasticity and thermal expansion coefficient mismatch of the composite constituents. The current study explores the feasibility of an alternative radical approach of incorporating silicon in the form of special nanoscale POSS molecules as an integral part of Pglass short-range and intermediate-range (i.e., chain) structures which would preserve the favorable rheological properties of the POSS/Pglass nanocomposite dispersion in the liquid state during processing and compliance of the POSS/Pglass matrix nanocomposite film or thick sheet while significantly lowering its surface tension properties. The resulting POSS/Pglass matrix nanocomposite materials should possess mechanical and melt rheological properties such as a combination of transparency (optical clarity), improved thermo-mechanical properties, and lower surface tension than that of current pure Pglasses and borosilicate glass matrix composites reported in the literature [25, 26, 28-39] for potential uses in security glazing, armor structures, monitoring windows and impact resistant transparent panels. While the POSS/Pglass matrix nanocomposite materials and processing technology reported in the current study are different from conventional ceramic matrix composites (CMCs) and melt blending of polymer matrix nanocomposites and composites (PMCs) to maximize properties, it is hoped that the reported obtained results of the current study may shed light on the molecular dynamics of CMCs and PMCs in general during processing at the nanometer length scales, a subject of current intense study by academic and industry researchers $[40,41]$

The polyhedral oligomeric silsesquioxane (POSS) used as nanofiller materials in the current study represent a unique nanochemical materials platform that have been widely studied and found to be highly effective nanofiller in different composite materials reported in the literature [42-46]. It is worthy to note that POSS is composed of well-defined silicon based nanoscale cage structures that possess incompletely condensed or completely condensed frameworks having the form of $\mathrm{SiO}_{1.5}$. In addition, this intermediate silicon-oxygen framework consisting of rigid crystalline silica-like cage structures shows excellent thermal, flammable 
resistance and oxidative stability [42, 47-49]. POSS can be incorporated into polymeric matrices by several methods such as grafting, copolymerization and blending [50-56]. Further, POSS is an excellent nanofiller which includes inorganic and organic parts in one structure which can show organic-inorganic hybrid properties. POSS can be used as nanofiller to improve limited properties of Pglass, such as thermal and mechanical properties.

The phosphate glass used as a matrix material in the current study has remarkably low glass transition and processing temperatures as compared to silicate based glasses. As previously reported, inorganic phosphate glasses are usually considered as polymeric materials because of their chain structures similar to polymer structure [21]. The basic structure of phosphate glass networks is based on the phosphate anion tetrahedron [23], which is denoted by $Q$ ', where the ' $i$ ' is the number of bridging oxygens on the unit structure of the phosphate anion tetrahedral structure. There are various phosphate glasses compositions reported in the literature including different alkali metals, e.g. $\mathrm{Li}, \mathrm{Na}$ and $\mathrm{K}$, that are the crucial part of phosphate glass network formation [20]. One of these compositions is alkali zinc phosphate glass (AZP) which shows chemically durable properties and has the following composition: $x \mathrm{M}_{2} \mathrm{O}+y \mathrm{ZnO}+z \mathrm{P}_{2} \mathrm{O}_{5}$ (where $x<0.25, y<0.5,0.29<z<0.5$ ), $\mathrm{M}$ is an alkali such as $\mathrm{Li}, \mathrm{Na}$ and $\mathrm{K}$, and numbers are in mole fractions) [21]. AZP glasses have high $\mathrm{T}_{\mathrm{g}}$ values as compared with that of tin fluorophosphates (TFP) glasses [19], which shows very low $T_{g}$ values ranging between $90^{\circ} \mathrm{C}$ and $140^{\circ} \mathrm{C}$ and favorable rheological properties similar to that reported in the current study. The low- $T_{g}$, favorable rheological properties and other desirable characteristics of the TFP glasses make them promising materials for a wide range of uses in diverse application areas, including optoelectronic components, biomedical/bioengineering, and protective coatings. To our knowledge, there is no prior reported research study on POSS/Pglass matrix nanocomposites as in the current study, making it easy to say that the current work is important and timely and may provide a basis upon which future studies on the interesting concept of phosphate glass matrix nanocomposites can be launched.

This study is part of a long-range research project aimed at developing novel optomechanical glass matrix nanocomposites with controllable chemistry and properties (e.g., strength and light transmittance) for diverse applications, and at discovering novel tunable structure-property relations for the nanocomposites. It is worthy to note that the glass and POSS synthesis parameter space is potentially broad because it is a function of the reactive hydroxyl functionalities of the glass composition and the various chemical functionalities of the prescribed POSS chemistry. The POSS chemistry platform is a diverse nanochemical platform that is 
chemically tailored to be compatible with appropriate chemicals and materials as already mentioned. By working with the industrial manufacturer of these innovative POSS nanochemicals, it is reasonable to expect that a range of chemical reaction mechanisms will result from this long-range research project that is likely to yield special products with controllable properties to meet the vast requirements of diverse applications. While the current work is focused on low- $T_{g}$ Pglass and POSS systems as a proof of concept of the novel glass matrix nanocomposites materials platform, it is hoped that the work described here will provide a fundamental basis for a better understanding of application of the novel materials chemistry strategy to other glass chemistries and of new facile methods of modifying the properties of pure glasses at molecular length scales with enhanced benefits including several orders of magnitude improvement in their reinforcing ability of pure glass and pure polymer matrices than traditional glass fibers and particles with micrometer length scales.

\section{Experimental Methods}

\subsection{Materials and preparation of nanocomposites}

Trisilanol phenyl POSS (TSP-POSS, $\mathrm{C}_{42} \mathrm{H}_{38} \mathrm{O}_{12} \mathrm{Si}_{7}$, solid powder) was supplied by Hybrid Plastics Co., Ltd. Analytical grade reagents used \{i.e., tin(II) oxide ( $\mathrm{SnO})$, tin(II) fluoride $\left(\mathrm{SnF}_{2}\right)$ and ammonium dihydrogen phosphate $\left.\left(\left(\mathrm{NH}_{4}\right) \mathrm{H}_{2} \mathrm{PO}_{4}\right)\right\}$ were purchased from Sigma-Aldrich and used as received. The neat tin fluorophosphates glass (hereinafter referred to as Pglass) and Pglass matrix nanocomposites incorporating POSS was synthesized with molar composition $50 \mathrm{SnF}_{2}+20 \mathrm{SnO}+30 \mathrm{P}_{2} \mathrm{O}_{5}$ and various concentrations of POSS ranging from $0 \mathrm{wt}$. $\%$ to $10 \mathrm{wt} \%$ via a one pot chemical synthesis method. The chemical structures of the Pglass [9] and TSPPOSS are shown in Fig. 1. The synthesis method was conducted using analytical grade powders of $\mathrm{SnF}_{2}, \mathrm{SnO},\left(\mathrm{NH}_{4}\right) \mathrm{H}_{2} \mathrm{PO}_{4}$, and TSP-POSS in the required stoichiometric ratios that were homogeneously mixed in a mortar. The obtained mixtures were subsequently melted in a carbon crucible at a temperature of $430^{\circ} \mathrm{C}$ for $30 \mathrm{~min}$ in a furnace. The resulting melts were poured into a pre-shaped steel mold at ambient temperature to yield glass disk specimens with $10 \mathrm{~mm}$ diameter and $2 \mathrm{~mm}$ thick dimensions as depicted in Fig. 2. The obtained samples were subsequently annealed around their glass transition temperature ranging from $130-160^{\circ} \mathrm{C}$ for 90min depending on the POSS content in the compositions. A portion of the obtained sample was ground into powder and then sifted through a sieve with $150 \mu \mathrm{m}$ mesh for thermal and chemical characterizations. In a second preparation method, 5 wt.\% POSS and premade Pglass 
particles were manually ground and mixed, heated in a carbon crucible maintained at $300^{\circ} \mathrm{C}$ for $10 \mathrm{~min}$ in the furnace, and subsequently cooled down to ambient temperature. The morphology and dispersion of the POSS in the Pglass matrix nanocomposites will be compared as a function of the preparation method used (i.e., synthesis method and physical blending).

\subsection{Measurements}

\subsubsection{Differential Scanning Calorimetry (DSC)}

A DSC (PerkinElmer Pyris Diamond ${ }^{\circledR}$ DSC) equipped with an intracooler and a computer for data acquisition and analysis was used in a dry nitrogen atmosphere to determine the glass transition temperature $\left(\mathrm{T}_{\mathrm{g}}\right)$ of the samples. Approximately 150 micrometer glass particle size weighing about $15 \mathrm{mg}$ were used for the DSC measurements in the temperature range from $30^{\circ} \mathrm{C}$ to $180^{\circ} \mathrm{C}$ and $a 10^{\circ} \mathrm{C} / \mathrm{min}$ heating rate in an alumina crucible under a nitrogen atmosphere. The samples were subjected to a heat-cool-heat cycle, with cooling accomplished by intracooler cooling system prior to reheating. The glass transition temperature data obtained in the second heating run are reported in this article.

\subsubsection{Thermogravimetric analysis (TGA)}

TGA was carried out on the samples using TA instrument $Q 500^{\circledR}$ operating from $30^{\circ} \mathrm{C}$ to $600^{\circ} \mathrm{C}$ at a heating rate of $10{ }^{\circ} \mathrm{C} / \mathrm{min}$ with $10 \mathrm{~mL} / \mathrm{min} \mathrm{N}_{2}$ sample purge flow to investigate the thermal stability of the samples. The thermal degradation temperature was taken as the onset temperature of thermal degradation using the universal analysis software from TA instruments.

\subsubsection{Attenuated total reflectance Fourier transform infrared spectroscopy (ATR-FTIR)}

ATR-FTIR measurements were conducted on a Fourier transform spectrometer (Thermo Scientific Nicolet $6700^{\circledR}$ ) equipped with Smart iTR ${ }^{\mathrm{TM}}$ Attenuated Total Reflectance (ATR) Sampling Accessory having a single bounce diamond crystal, at an ambient condition in the frequency region from $650-4000 \mathrm{~cm}^{-1}$ for each sample. In all cases, 32 scans at a resolution of $4 \mathrm{~cm}^{-1}$ were used to record the spectra. The desired amount of the samples was ground to a fine powder (less than $150 \mu \mathrm{m}$ particle size) and analyzed on the diamond ATR surface. 
2.2.4. Atomic force microscopy (AFM)

Surface topography of the samples was characterized by AFM (a Dimension Icon AFM, Bruker) in tapping mode for both height and phase image using RTESPA300 ${ }^{\circledR}$ probe with a spring constant $(k)$ of $40 \mathrm{~N} / \mathrm{m}$ attached to a silicon tip (antimony $(\mathrm{n})$ doped $\mathrm{Si}$ ) to analyze the fracture surface of bulk Pglass and nanocomposites samples. AFM measurements were performed to quantify the difference between the neat Pglass and the POSS/Pglass nanocomposites. To investigate the surface topography of POSS/Pglass nanocomposites, the samples were fractured using a diamond glass cutter and the smooth fractured surfaces were used for the AFM experiments. The PeakForce Quantitative Nanomechanical Property Mapping (QNM) mode [57, 58] was performed to measure the moduli on the fracture surfaces of the samples, using the modulus data of polystyrene film as the reference. The elastic modulus was fitted with the Derjajuin-Muller-Toporov (DMT) model [58, 59] using Nanoscope Analysis software (Bruker).

\subsubsection{X-ray photoelectron spectroscopy (XPS)}

XPS spectra were obtained using a Kratos AXIS $165^{\circledR}$ spectrometer equipped with monochromatic Al-Ka X-rays at $12 \mathrm{kV}$ and $12 \mathrm{~mA}$ as the excitation radiation in UHV, $5 \times 10^{-9}$ torr. The cross-sectional surfaces of the bulk Pglass and naocomposites samples were analyzed because fractured cross section surface is compositionally most representative of the bulk of the samples. To reduce surface charging on the glass samples, a charge neutralizer was used. The $\mathrm{O}$ 1s spectra collected from the Pglass and nanocomposites samples were fit using a Gaussian curve-fitting method in ORIGIN ${ }^{\circledR}$ software.

\subsubsection{Scanning electron microscopy (SEM) - Energy Dispersive X-ray spectroscopy (EDX)}

To investigate the morphology of the POSS-containing Pglass matrix nanocomposites, the samples were fractured and coated with silver using a Quorum Emitech K550X sputter coater to make the samples conductive. A Zeiss Sigma VP ${ }^{\circledR}$ field emission scanning electron microscope (SEM) operating at $20 \mathrm{kV}$ with an attached energy-dispersive X-ray spectroscopy (EDX) having a Thermo Scientific UltraDry EDX detector was used to obtain the morphology and elemental compositions with $\mathrm{NSS}^{\circledR}{ }^{\circledR}$ micro-analysis software on the surfaces of the fractured neat Pglass and nanocomposites incorporating POSS. 


\subsubsection{Transmission electron microscopy (TEM)}

TEM measurements were performed (Zeiss $900^{\circledR}$ ) with an acceleration voltage of $50 \mathrm{kV}$ to identify the POSS molecules in the nanocomposites. Specimens for TEM were prepared by addition of Pglass nanocomposite particles (Max. $53 \mu \mathrm{m}$ diameter) in an epoxy resin matrix which was cured for $36 \mathrm{hr}$ at $70^{\circ} \mathrm{C}$. The samples were cut and trimmed using a microtome blade and the specimen sections were placed in 200 mesh copper grids for observation.

\subsubsection{Melt rheology}

Rheological behavior of the samples was studied using an Anton Paar Physica MCR $501{ }^{\circledR}$ with a $25 \mathrm{~mm}$ diameter parallel-plate geometry at temperatures ranging from $270^{\circ} \mathrm{C}$ to $290^{\circ} \mathrm{C}$. A linear strain of $1 \%$ was used for all the small-amplitude oscillatory shear tests based on the result of a strain sweep test to determine the linear viscoelastic region. Dynamic frequency sweep tests over a frequency range of 0.1 - $200 \mathrm{rad} / \mathrm{s}$ were carried out on the samples. All the rheological experiments were conducted in a nitrogen atmosphere to preclude oxidative degradation of the samples. The obtained data replicated to within about $10 \%$ from sample to sample

\subsubsection{Solid-state NMR}

Solid-state ${ }^{31} \mathrm{P}$ magic angle spinning (MAS) NMR spectra of the samples were obtained on a Bruker Avance III 600 (14.1 T) NMR instrument using a $4 \mathrm{~mm}$ broadband MAS probe spinning at $12.5 \mathrm{kHz}$ following standard acquisition conditions and ${ }^{1} \mathrm{H}$ decoupling. The $1 \mathrm{D}$ direct polarization (DP) NMR spectra were obtained using a single pulse Bloch decay with a $240 \mathrm{~s}$ recycle delay with 16 scan averages, while the $1 \mathrm{D}{ }^{1} \mathrm{H}^{3}{ }^{31} \mathrm{P}$ cross polarization (CP) MAS NMR where obtained using a $1 \mathrm{~ms}$ contact time and a $2 \mathrm{~s}$ recycle delay, and $8 \mathrm{~K}$ scan averages. The

${ }^{31} \mathrm{P}$ NMR chemical shift was referenced to the external secondary standard $\left(\mathrm{NH}_{4}\right) \mathrm{H}_{2} \mathrm{PO}_{4} \delta=0.8$ $\mathrm{ppm}$ with respect to phosphoric acid $\delta=0 \mathrm{ppm}$. The ${ }^{19} \mathrm{~F}$ MAS NMR spectra were obtained on a Bruker Avance III 400 (9.6 T) NMR instrument using a $2.5 \mathrm{~mm}$ broadband MAS probe spinning at $25 \mathrm{kHz}$. A rotor synchronized Hahn Echo with a $120 \mathrm{~s}$ recycle delay were used to obtain the 1D ${ }^{19} \mathrm{~F}$ NMR DP spectrum. The ${ }^{19} \mathrm{~F}$ chemical shift was referenced to the secondary standard 
ammonia trifluoro acetate $\delta=-72 \mathrm{ppm}$ with respect to $\mathrm{CFCl}_{3} \delta=0 \mathrm{ppm}$. Deconvolutions were performed in $\mathrm{DMFIT}^{\circledR}[60]$.

\subsubsection{Experimental error analysis}

The reported experimental data are obtained from at least three samples and the obtained data are reported as averages with standard deviations and shown as error bars in the relevant tables and figures, respectively.

\section{Results and discussion}

\subsection{Thermal properties}

The thermal stability of the samples is depicted in Fig. 3 showing the TGA curves of the neat Pglass and the nanocomposites samples. Within the experimental temperature range tested (i.e., $30^{\circ} \mathrm{C}$ to $600^{\circ} \mathrm{C}$ ), there is no significant difference in the on-set temperature of thermal degradation between the neat Pglass and nanocomposites. Clearly, the initial thermal degradation respectively occurred at $367^{\circ} \mathrm{C}$ and $365^{\circ} \pm 5^{\circ} \mathrm{C}$ for the neat Pglass and nanocomposites as Fig. 3(b) shows. All the samples showed only $4 \pm 1$ wt. $\%$ of decomposition at elevated temperature $600^{\circ} \mathrm{C}$. The observed relative insignificant effect of POSS on the thermal stability of the samples is ascribed to formation of new $\mathrm{P}-\mathrm{O}-\mathrm{Si}$ or $\mathrm{Sn}-\mathrm{O}-\mathrm{Si}$ bonds via condensation reaction between $-\mathrm{OH}$ in the POSS and $-\mathrm{OH}$ in the Pglass during the synthesis of the samples $[61,62]$ that are relatively thermally stable like the Si-O-Si bond in the POSS and $\mathrm{P}-\mathrm{O}-\mathrm{P}$ or P-O-Sn in the Pglass.

The glass transition temperatures $\left(\mathrm{T}_{\mathrm{g}}\right)$ of the samples were obtained via DSC as already described in the experimental section. The $T_{g}$ of the neat Pglass was found to be $121.6^{\circ} \mathrm{C}$ and the $\mathrm{T}_{\mathrm{g}}$ of the nanocomposites steadily increased with increasing POSS content (up to a $\mathrm{T}_{\mathrm{g}}=$ $147.6^{\circ} \mathrm{C}$ for $10 \mathrm{wt} \%$ POSS nanocomposite) as shown in Fig. 4. This observation indicates a significant influence of POSS on the glass transition relaxation process in the Pglass matrix of the nanocomposites that is attributed to the bulky structure of POSS molecules like other researchers have reported in the literature [45]. In general, POSS has rigid silsesquioxane cages at the center of molecules and organic groups around the cages. The interaction of the organic groups around the cages and matrix materials is known to strongly influence POSS 
nanocomposites properties including glass transition temperature. In addition, the open cage type structure of POSS used in this study has silanol groups that can be reactive via condensation reaction [62] with other -OH groups of Pglass, providing chemical bonds between POSS cage and Pglass matrix materials. This suggests that the bulky and rigid POSS molecules are grafted onto the main chains of the Pglass thereby causing the observed increase of glass transition temperature of the Pglass matrix nanocomposites via restriction of Pglass chains mobility.

\subsection{Chemical structure analysis}

The chemical structure of the samples was probed by FTIR, XPS, MAS NMR following standard methods reported in the literature as already described in the experimental section. The FTIR spectra of the samples in Fig. 5 clearly shows a peak around $1070 \mathrm{~cm}^{-1}$ that is

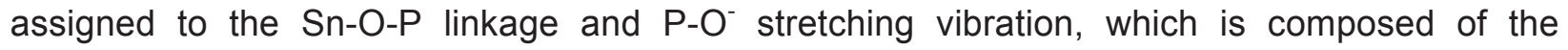
phosphate linked to a non-bridging oxygen in the Pglass structure [63-66]. This peak is relatively broader as the amount of POSS is increased in the nanocomposites due to the formation of new chemical P-O-Si bond assigned to $1160 \mathrm{~cm}^{-1}$ [61]. The bond just mentioned results from condensation reaction of $-\mathrm{OH}$ in the POSS and $-\mathrm{OH}$ in the Pglass during the chemical synthesis of the samples. The additional peak of Si-O-Si symmetric stretching occurring at $1100 \mathrm{~cm}^{-1}$ is ascribed to the core cages of POSS [61]. The peak near $1015 \mathrm{~cm}^{-1}$ is associated with the ($\left.\mathrm{PO}_{3}\right)^{2-}$ end groups which becomes broader as the amount of POSS in the nanocomposite is increased [67]. This last observation is probably caused by the overlapping of the $1015 \mathrm{~cm}^{-1}$ peak with the Si-O stretching vibration peak assigned to $1028 \mathrm{~cm}^{-1}$ from the POSS structure [68]. The peaks near $920 \mathrm{~cm}^{-1}$ and $740 \mathrm{~cm}^{-1}$ are respectively due to the P-O-P asymmetric and symmetric stretching vibrations $[63,66]$. As expected, location and intensity of these two P-O-P peaks are not changed by the presence of POSS in the nanocomposites, indicating that the main structure of the Pglass is not changed significantly during the synthesis of the hybrid POSS/Pglass nanocomposites samples. In addition, the peak near $840 \mathrm{~cm}^{-1}$ is assigned to the stretching mode of P-F bond, which is the terminal bond in the Pglass structure [66, 69]. These P-F bonds are diminished as the amount of POSS in the nanocomposite is increased. This last observation is conjectured to be caused by the bonding competition between $\mathrm{F}$ and $\mathrm{Si}-\mathrm{O}$ to phosphorous that leads to a decrease in the P-F bonds due to its replacement by the new P-O$\mathrm{Si}$ bonds in the nanocomposite samples. It is worthy to note that the above FTIR results provide 
confirmatory evidence of formation of chemical bonds between Pglass and POSS under the synthesis conditions of the samples used in this study.

Oxygen 1s X-ray photoelectron spectroscopy (XPS) was used to measure the ratio of the non-bridging oxygen to bridging oxygen in the Pglass and nanocomposites. The $O$ 1s spectra of the neat Pglass and nanocomposites incorporating $5 \mathrm{wt} \%$ POSS are deconvoluted to reveal the peaks that contain two main components representing non-bridging oxygen (NBO) and bridging oxygen (BO) in the Pglass (see Fig. 6). Brow et al. [70] reported results of a high ratio of $\mathrm{NBO}$ to $\mathrm{BO}(19: 1)$ in the $\mathrm{O}$ 1s spectra of $50 \mathrm{SnF}_{2}-20 \mathrm{SnO}-30 \mathrm{P}_{2} \mathrm{O}_{5}$ glass. In addition, Wagner et al. [71] reported the result of $7.8 \%$ oxygen atoms over the $\mathrm{BO}$ bonds in the same Pglass composition. According to our data in Fig. 6(a), 5.1\% of BO and $94.9 \%$ of NBO are observed in the neat Pglass used, which is consistent with the result reported by Brow et al. [70]. In addition, the observed spectrum for the neat Pglass has a peak centered near the lower binding energy $531.3 \mathrm{eV}$ for the $\mathrm{BO}$ and the other peak is centered near $529.8 \mathrm{eV}$ for the NBO in the neat Pglass, respectively [72]. In the Pglass, the BO are associated with P-O-P linkage

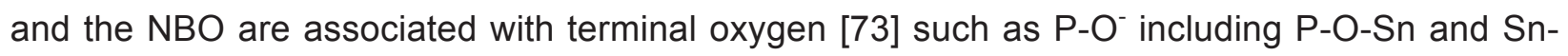
$\mathrm{O}-\mathrm{Sn}$. As reported in the literature [74, 75], $\mathrm{P}=\mathrm{O}$ and non-bridging $\mathrm{P}_{-} \mathrm{O}^{-}$are not resolvable and the intensity of the XPS spectra of these oxygens is referred to as the NBO because of the peaks assigned to double-bonded $(P=O)$ oxygens are nearly coincident with the NBO. Brow [76] reported that $\mathrm{P}=\mathrm{O}$ bonds are not expected to be detected separately in the $\mathrm{O}$ 1s spectra because $\mathrm{P}=\mathrm{O}$ could be found only in the ultraphosphate compositions (e.g. $\left.\left(\mathrm{P}_{2} \mathrm{O}_{5}\right)>50 \mathrm{~mol} \%\right)$ in the XPS analysis. As shown in Fig. 6(b) the ratio of BO to NBO in the 5 wt.\% POSS nanocomposite indicate a significant $40 \%$ increase from $5.1 \%$ of the neat Pglass. This result is probably caused by the BO in Si-O-Si of POSS and the new Si-O-P linkage between Pglass and POSS in the nanocomposites. Onyiriuka [74] reported that the BO of Si-O-Si and the NBO (e.g. $\mathrm{Si}-\mathrm{O}-\mathrm{M}^{+}$) can be distinguished by the O1s XPS spectrum similar to the oxygen in the Pglass, and other researchers have reported BO peaks centered near $531 \mathrm{eV}$ for Si-O-Si that overlaps the binding energy of P-O-P linkage [77]. Overall, the obtained $40 \%$ of BO can be explained by several bridging linkages like the P-O-P, Si-O-Si and Si-O-P linkages that possibly belong to the $\mathrm{BO}$ in the $5 \mathrm{wt}$ \% POSS nanocomposite sample. Clearly, the above results confirm the desirable chemical reaction between the POSS and the Pglass as a facile method of incorporating molecular silica into the chemical structure of the Pglass matrix nanocomposite with enhanced benefits described later. 
Lastly, the chemical structure was characterized using both ${ }^{19} \mathrm{~F}$ and ${ }^{31} \mathrm{P}$ solid-state nuclear magnetic resonance (SSNMR). Figure $7(\mathrm{a})$ shows the ${ }^{19} \mathrm{~F}$ MAS NMR for Pglass with increasing concentration of POSS. The spectra are dominated $(\sim 88 \%)$ by a resonance at $\delta=-$ $58 \mathrm{ppm}$ (and associated spinning sidebands) which has been assigned to a P-F environment [78]. There is also a $\mathrm{F}$ environment observed at $\delta=-48 \mathrm{ppm}(11 \%)$ assigned to $\mathrm{SnF}_{2} \mathrm{species}$ [79] and a minor species at $\delta \sim-120(\sim 1 \%)$ assigned to a $F$ in a mixed tin oxide environment (spectral deconvolutions are shown in Figure 7(b)) These results show that there are no large changes in the $\mathrm{F}$ environments and that the $\mathrm{P}-\mathrm{F}$ linkage is retained in the glass structure during the formation of the nanocomposites. The ${ }^{31} \mathrm{P}$ MAS NMR (Fig. 7(c)) and ${ }^{1} \mathrm{H}^{31}{ }^{31} \mathrm{P}$ CPMAS NMR spectra (Fig. 7(d)) show the central isotropic resonance shift region for samples with the addition of the POSS into the Pglass matrix nanocomposite. These spectra are assigned to the overlapping $Q^{1}$ and $Q^{0}$ species at $\delta=-18.8$ and -11.3 ppm., where the numbers 1 and 0 indicate the number of bridging oxygen connected to phosphorous in the Pglass structure $[9,23]$. A few comments are warranted on these resonance assignments. It has been previously argued that substitution of a $\mathrm{F}$ for a bridging $\mathrm{O}$ within the phosphate polyhedron has minimal effect on the ${ }^{31} \mathrm{P}$ chemical shift for metaphosphate $\mathrm{Q}^{2}$ species (two bridging oxygens and two non-bridging oxygens per phosphate or one bridging oxygen, one fluorine and two non-bridging oxygens per phosphate), while formation of a terminal P-F leads to the depolymerization of the $\mathrm{Q}^{2}$ phosphate $[80,81]$. For pure tin phosphate glasses $x \mathrm{SnO}(1-x) \mathrm{P}_{2} \mathrm{O}_{5}$ the $\mathrm{Q}^{2}$ phosphate species was observed between $\delta=-35$ and -32 ppm [82, 83], arguing that $Q^{2}$ phosphate species (fluorinated or non-fluorinated) are not present in the TFP glass. For pure tin phosphate glass the $\mathrm{Q}^{1}$ and $\mathrm{Q}^{0}$ phosphate species were reported between $\delta=-20$ and $-15 \mathrm{ppm}$ and $\delta=-11$ and $-9 \mathrm{ppm}$, respectively [82]. The assignment of the broad resonance observed at $\delta=-18.8$ ppm to a ($\left.\mathrm{OP}\left(\mathrm{O}^{-}\right)_{2} \mathrm{~F}\right) \mathrm{Q}^{1}$ phosphate species is consistent with the assignment previously reported for TFP glasses and composites [84]. The minor resonance at $\delta=-11.3 \mathrm{ppm}$ in the pure TFP glass is assigned to orthophosphate $Q^{0}$ phosphate species. These NMR results show that there are no huge structural or chemical changes in the Pglass structure except for a minor increase in the $\delta$ $=-11.3 \mathrm{ppm}$ resonance with the increasing POSS addition. This is clearly evident in Fig. 7(e) where a spectral deconvolution is shown. The relative concentration of the $Q^{1}$ to $Q^{0}$ phosphate species of all the chemically synthesized samples being displayed in Table 1 for easy comparison. Note that as the amount of POSS in the nanocomposite increased the ratio of $\mathrm{Q}^{0}$ to $Q^{1}$ increased, indicating that shorter inorganic Pglass chains are formed with the addition of POSS, or that this increase in the $\delta=-11.3$ ppm resonance may reflect direct bonding between POSS and the TFP glass. The reaction between $-\mathrm{OH}$ of Pglass and $-\mathrm{OH}$ of POSS would result 
in the formation of P-O-Si linkages that are predicted to occur with a ${ }^{31} \mathrm{P}$ chemical shift near $\delta=$ -10 to $-12 \mathrm{ppm}$ [85]. In this study there is not a distinct peak for this proposed linkage species. The ${ }^{1} \mathrm{H}-{ }^{31} \mathrm{P}$ CPMAS NMR spectra (Fig. 7(d)) are similar to the DP ${ }^{31} \mathrm{P}$ MAS NMR spectra, but are much weaker, representing only $\sim 2 \%$ of the total ${ }^{31} \mathrm{P}$ signal. Also note that with increasing POSS concentration there is an emphasis of the $\delta=-11.30 \mathrm{ppm}$ in the CPMAS ${ }^{31} \mathrm{P}$ NMR. These CPMAS results demonstrate that for the original TFP glass there is low water and $\mathrm{OH}$ concentrations, confirming previously reported excellent durability for this glass composition. These results are remarkably consistent with the FTIR data already described.

\subsection{Melt rheology}

As shown in Fig. 8 the neat Pglass and nanocomposites revealed a Newtonian behavior (or constant viscosity with shear rate) under steady shear flow conditions at $270^{\circ} \mathrm{C}$ except the low shear rate region of the neat Pglass [17]. As the amount of POSS increased in the nanocomposites, the viscosity of the nanocomposites gradually increased. The obtained results showed that addition of POSS in the nanocomposites gave higher viscosity due to the influence of the bulky POSS molecules in the liquid Pglass matrix [45]. It is noteworthy that this result is consistent with the FTIR and XPS analysis already discussed in the previous sections. The significantly low viscosity observed for the neat Pglass at the low shear rate may be due to the test instrument limitation in the very low viscosity regime. The significant increase in the viscosity of the Pglass matrix with small additions of POSS is remarkable and may provide a facile method of changing the deformation and flow properties of glass matrix nanocomposites during shaping and forming while still preserving the optical properties of the glass as already mentioned.

Complex viscosities of the neat Pglass and nanocomposites under small amplitude oscillatory shear flows are shown in Fig. 9(a). As expected, this figure shows an increase in the complex viscosity with increasing amount of POSS in the nanocomposites in the whole frequency range tested. In addition, Newtonian fluid behavior was observed for all the samples under the reported test conditions. As shown in Fig. 9(b, c), it can be seen that addition of POSS causes an increase in both the dynamic storage and loss moduli, respectively. The data scattering observed in the low frequency region for the neat Pglass and nanocomposite (2 wt.\% POSS) may be due to instrument limitation in the very low storage modulus regime that is characteristic of the samples. Fig. 9(d) shows the so-called Han plots for the samples [86, 87], 
which shows the relation between storage modulus and loss modulus at similar frequency. The slope of the storage modulus versus loss modulus significantly decreased as the amount of POSS increased in the nanocomposites as clearly evident in Fig. 9(d). It is worthy to note that the change of slope in this figure indicates significant difference in the structure of the nanocomposites composed of the matrix and filler materials at a fixed temperature [86]. The rheology of non-entangled melts like the current Pglass melts is well described by a modified Rouse theory [88]. Using this theory the rheological characteristics of alkali zinc phosphate (AZP) glass was interpreted as undiluted organic polymers of low molecular weight as previously reported $[89,90]$. The dynamic storage modulus and dynamic loss modulus of the current samples are expected to be predicted by this theory. Briefly, the Rouse model describes the complex dynamic viscosity according to the following equation;

$$
\eta^{*}(\omega)=\frac{\rho R T}{M} \sum_{p=1}^{N} \frac{\tau_{p}}{1+i \omega \tau_{p}}
$$

Here, the materials have a density $\rho$, molecular weight $M$, and a set of relaxation times $\left\{\tau_{1}, \tau_{2}\right.$, $\left.\tau_{3}, \ldots, \tau_{N}\right\}$ at absolute temperature $T$ and angular frequency $\omega$. Here, $R$ is the ideal gas law constant and $i=\sqrt{-1}$. This result simplifies with one relaxation time $\mathrm{T}$ :

$$
\eta^{*}(\omega)=\frac{\rho R T}{M} \frac{\tau}{1+i \omega \tau}
$$

The $\omega$ dependence at any $T$ can be summarized with two fit parameters $\eta_{0}$ and $\tau$. Here, a zero shear viscosity $\eta_{0}$ was defined by Sammler et al. [90] as

$$
\eta_{0}=\frac{\rho R T \tau}{M}
$$


By using the definition,

$$
\eta^{*}(\omega)=\left|\eta^{*}(\omega)\right| \exp \left\{-\phi_{\eta}(\omega)\right\}
$$

where,

$$
\phi_{\eta}(\omega)=\tan ^{-1}\{\omega \tau\}
$$

the magnitude of the complex viscosity is given as

$$
\left|\eta^{*}(\omega)\right|=\eta_{0}\left\{1+(\omega \tau)^{2}\right\}^{-1 / 2}
$$

As reported by Adalja et al. [91], the 1-parameter Rouse model (equation 6) for the dynamic shear data of the Pglass agrees very well at low values of the angular frequency, but significant deviation appeared in the higher frequency region. Therefore, the 2-parameter Rouse model was applied in the current study consistent with the assumption of two kinds of units in the Pglass. The 2-parameter Rouse model more accurately models the frequency dependence of the complex viscosity according to the equations below [91]. In the 2-parameter Rouse model, the complex viscosity as a function of frequency can be described as

$$
\eta^{*}(\omega)=\frac{\rho R T}{M}\left\{\frac{\tau_{1}}{1+i \omega \tau_{1}}+\frac{\tau_{2}}{1+i \omega \tau_{2}}\right\}
$$

and two constants with the units of viscosity

$$
\eta_{1}=\frac{\rho R T \tau_{1}}{M} \quad \text { and } \quad \eta_{2}=\frac{\rho R T \tau_{2}}{M}
$$


Equations (7) and (8) can be combined to give the magnitude of the complex viscosity as the following equation (9):

$$
\left|\eta^{*}(\omega)\right|=\left\{\left[\frac{\eta_{1}}{1+\left(\omega \tau_{1}\right)^{2}}+\frac{\eta_{2}}{1+\left(\omega \tau_{2}\right)^{2}}\right]^{2}+\omega^{2}\left[\frac{\eta_{1} \tau_{1}}{1+\left(\omega \tau_{1}\right)^{2}}+\frac{\eta_{2} \tau_{2}}{1+\left(\omega \tau_{2}\right)^{2}}\right]^{2}\right\}^{1 / 2}
$$

As shown in Fig. 10 the theoretical predictions of equation (9) show agreement with the obtained experimental data. The $\tau_{i}$ and $\eta_{i}$ values are shown in Table 2 for the neat Pglass and nanocomposites. The fitting was carried out using Origin ${ }^{\circledR}$ software.

As shown in Fig. 11 the viscosity of the neat Pglass and all nanocomposites samples having different POSS concentrations decreased as the temperature increased, facilitating the processability of the materials at elevated temperatures. To determine the flow activation energy of the neat Pglass and nanocomposites in the range of temperature explored, an Arrhenius type equation was applied over the specific experimental temperature range due to the restriction of using WLF equation at temperatures close to the glass transition temperature [91]. The TimeTemperature Superposition shift factor $\alpha_{T}$ can be described as follows

$$
\alpha_{T}=\frac{\eta_{0}(T)}{\eta_{0}\left(T_{0}\right)}
$$

Here, $T_{0}$ is reference temperature, $280^{\circ} \mathrm{C}$, and shift factor $\alpha_{T}$ can be fitted with temperature according to the following equation:

$$
\alpha_{T}=\exp \left[\frac{\Delta \mathrm{H}}{R}\left(\frac{1}{T}-\frac{1}{T_{0}}\right)\right]
$$

where, $\Delta H$ is the flow activation energy and $R$ is the universal gas constant. Equation (11) can be rewritten as follows. 


$$
\log \alpha_{T}=\frac{\Delta \mathrm{H}}{2.303 R}\left(\frac{1}{T}-\frac{1}{T_{0}}\right)
$$

The activation energies $(\Delta \mathrm{H})$ were calculated from slopes $(\Delta \mathrm{H} / 2.303 \mathrm{R})$ of lines in Fig. $11(\mathrm{~b})$ as indicated by equation (12), using the experimental data for each sample displayed in Fig. 11(a); and the calculated activation energies is shown in Fig. 11(c). It is clearly evident from Fig. 11(c) that the flow activation energy of the samples is independent of the POSS concentration within the range explored. This observation is thought to be beneficial in the shaping and forming of products made from the nanocomposites

\subsection{Morphological analysis}

Figure 12 shows SEM micrographs of the fracture surfaces of the neat Pglass and nanocomposites containing $10 \mathrm{wt} \%$ of POSS prepared via chemical synthesis as already described. Clearly, the samples showed featureless morphologies with no discernable microscale aggregation or phase separation in the POSS/Pglass matrix nanocomposites, confirming the homogeneous molecular-level dispersion of POSS in the Pglass matrix. Note that the white speck on the surface of the sample on the SEM images in Fig. 12 is shown for contrast and to show the remarkably smooth and homogeneous surface of the sample. As shown earlier in Fig. 2, the nanocomposites were observed to be clearly transparent indicating that the POSS is chemically reacted with the Pglass to yield a hybrid POSS/Pglass nanocomposite. This last point is supported by Fig. 13 that shows mapping images of elements (white spots) by SEM-EDX on the fracture surface of Pglass matrix nanocomposites incorporating 10 wt.\% POSS. Clearly, Fig. 13(c) and (d) shows that the carbon (C) and silicon (Si) of the POSS are homogeneously dispersed in the Pglass matrix composed of P (and O, Sn, $\mathrm{H}$ and $\mathrm{F}$, not shown).

AFM was used to investigate nanoscale morphology of the fracture surface of Pglass and nanocomposites and the obtained results are in Fig. 14. This figure shows homogeneously dispersed biphasic nanostructure as the concentration of the POSS in the nanocomposite is increased from $5 \mathrm{wt} \%$ to $10 \mathrm{wt} \%$ (see Fig. 14(d-f)). This nanoscale structure facilitates the observed transparency and enhanced rheological properties of the nanocomposites. 
In order to compare the structure of the chemically synthesized hybrid POSS/Pglass nanocomposite with that of the physically blended premade Pglass and POSS blend as described in the experimental section 2.1, the morphology of the latter was investigated and the obtained result is shown in Fig. 15. As expected, this figure clearly shows segregated POSS structures attached to the surface of the Pglass matrix as depicted in Fig. 15(a). This observation is corroborated by Fig. 15(b) which shows TEM image of aggregated nanostructured POSS molecules attached to the surface of the Pglass matrix in the nanocomposite. Note that the structure of the physically blended nanocomposite is remarkably different from that of the chemically synthesized nanocomposite (Fig. 12) as already described. Based on all the obtained results of this study a conjectured chemical bonding structure of the synthesized POSS/Pglass nanocomposite is depicted in Fig. 16. The current study will provide a basis for further elaboration of the proposed chemical structure model just mentioned and a better understanding of the structure-property relations of the novel nanocomposites materials platform in a future proposed study.

\subsection{Nanomechanical properties}

As a first step towards assessing the effect of the POSS on the mechanical properties of the POSS/Pglass nanocomposite, the nanomechanical properties of fractured surfaces of the neat Pglass and nanocomposites were investigated using AFM QNM ${ }^{\mathrm{TM}}$ (PeakForce $^{\mathrm{TM}}$ Quantitative Nanomechanical Mapping) mode as already described in the experimental section [57-59, 92]. The obtained results are summarized in Fig. 17 for easy comparison. To obtain the elastic modulus of the samples, the experimental data curve was fitted with the DerjaguinMuller-Toporov (DMT) model [59, 93]. Here, the elastic modulus is given by

$$
\mathrm{F}=\frac{4}{3} E \sqrt{R d^{3}}+F_{a d h}
$$

where $F$ is the force, $R$ is the tip radius, $d$ is the deformation, and $F_{a d h}$ is the maximum adhesion force. As clearly shown in Fig. 17(d) the addition of POSS to the Pglass matrix increased the surface modulus of the nanocomposites. Fig. 18 shows the average and standard deviation of the obtained moduli for five profiles on each sample. The average modulus increased from 1.55 
GPa to $6.28 \mathrm{GPa}$ as the amount of POSS was increased from 0 wt.\% (neat Pglass) to 10 wt.\% TSP-POSS. Overall, the results of this study point to novel "transparent" glass matrix nanocomposites with enhanced benefits for a number of wide ranging uses in applications, including biomedical engineering, thin films and coatings.

\section{Conclusions}

It can be concluded from the results of this study that novel POSS/Pglass nanocomposites can be prepared by chemically reacting the raw materials of Pglass and neat POSS using a glass synthesis and quench method to yield novel transparent glass matrix nanocomposites with improved controllable properties. Incorporation of the POSS in the Pglass matrix nanocomposite increased the glass transition temperature of the nanocomposite, suggesting that the relatively bulky POSS molecules reduce mobility of Pglass chains in the nanocomposites. The observed improved melt viscoelasticity of the nanocomposites is thought to be crucially important and desirable in the shaping/forming of parts from the nanocomposites and their use. Spectroscopic analysis of the samples via ATR-FTIR, XPS confirmed the chemical reaction of the POSS with Pglass matrix to yield novel transparent POSS/Pglass nanocomposite with excellent homogeneous distribution of the nanodispersed POSS phase with enhanced benefits for diverse applications already mentioned. The nanoscale dispersion of the POSS in the POSS/Pglass nanocomposite was confirmed by the obtained AFM and SEM-EDX data. Solid-state NMR data showed that the ratio $Q^{0}$ to $Q^{1}$ increases slightly as the addition of POSS was increased in the Pglass matrix, suggesting that the average length of the Pglass chains in the nanocomposites is smaller than that of the neat Pglass.

Nanomechanical properties of the fractured surface was investigated using AFM PeakForce Quantitative Nanomechanical Mapping (QNM) mode and the obtained results showed increased elastic modulus of nanocomposite surface with increasing concentration of the uniformly nanodispersed rigid POSS molecules in the nanocomposites. This study provides the first ever fundamental information on novel phosphate glass matrix nanocomposites incorporating POSS dispersed at the molecular level to yield interesting hybrid POSS/Pglass materials with enhanced benefits like optically transparency and improved stiffness (or modulus) that may be useful in a wide range of industrial applications such as biomedical device, optoelectronic components, impact resistant transparent panels and bioengineering. 


\section{Acknowledgements}

This work was supported by the U.S. National Science Foundation of Division of Materials Research through DMR-1360006. We thank Wei Guo (AFM), Dr. William Jarrett (NMR), Robert Holler (XPS) and Jessica Douglas (SEM \& TEM) for their technical assistance in data acquisition and analysis. The research work of J.U.O's former graduate students and postdocs is gratefully acknowledged. The NMR portion of this work (TMA) was performed at Sandia National Laboratories, a multi-program laboratory managed and operated by Sandia Corporation, a wholly owned subsidiary of Lockheed Martin company, for the U. S. Department of Energy's National Nuclear Security Administration under contract DE-AC04-94AL85000.

\section{References}

[1. Hussain, F., et al., Review article: polymer-matrix nanocomposites, processing, manufacturing, and application: an overview. Journal of composite materials, 2006. 40(17): p. 1511-1575.

2. Alexandre, M. and P. Dubois, Polymer-layered silicate nanocomposites: preparation, properties and uses of a new class of materials. Materials Science and Engineering: R: Reports, 2000. 28(1): p. 1-63.

3. Schmidt, D., D. Shah, and E.P. Giannelis, New advances in polymer/layered silicate nanocomposites. Current Opinion in Solid State and Materials Science, 2002. 6(3): p. 205-212.

4. Ray, S.S. and M. Okamoto, Polymer/layered silicate nanocomposites: a review from preparation to processing. Progress in polymer science, 2003. 28(11): p. 1539-1641.

5. Hanemann, T., Influence of particle properties on the viscosity of polymer-alumina composites. Ceramics International, 2008. 34(8): p. 2099-2105.

6. Kumar, S., et al., Fibers from polypropylene/nano carbon fiber composites. Polymer, 2002. 43(5): p. 1701-1703.

7. Andrews, R. and M.C. Weisenberger, Carbon nanotube polymer composites. Current Opinion in Solid State and Materials Science, 2004. 8(1): p. 31-37.

8. Ma, P.-C., et al., Dispersion and functionalization of carbon nanotubes for polymer-based nanocomposites: a review. Composites Part A: Applied Science and Manufacturing, 2010. 41(10): p. 1345-1367.

9. Urman, K. and J.U. Otaigbe, New phosphate glass/polymer hybrids-Current status and future prospects. Progress in Polymer Science, 2007. 32(12): p. 1462-1498.

10. Lai, Y., et al., Structural and electrochemical properties of polyurethanes/polyhedral oligomeric silsesquioxanes (PU/POSS) hybrid coatings on aluminum alloys. Materials Chemistry and Physics, 2009. 117(1): p. 91-98.

11. Miracle, D.B., et al., ASM handbook. Vol. 21. 2001: ASM international Materials Park, OH, USA.

12. Hull, D. and T. Clyne, An introduction to composite materials. 1996: Cambridge university press.

13. URMAN, K. and J. OTAIGBE. Morphology, crystallization kinetics and dynamic mechanical analysis of phosphate glass-polyamide 12 hybrid materials. in ANTEC... conference proceedings. 2004. Society of Plastics Engineers. 
14. Urman, K. and J. Otaigbe, Novel phosphate glass/polyamide 6 hybrids: miscibility, crystallization kinetics, and mechanical properties. Journal of Polymer Science Part B: Polymer Physics, 2006. 44(2): p. 441-450.

15. Rawal, A., et al., Detection of nanometer-scale mixing in phosphate-glass/polyamide-6 hybrids by $1 H-31 P$ NMR. Chemistry of materials, 2006. 18(26): p. 6333-6338.

16. Rawal, A., et al., Promotion of the $y$-phase of polyamide 6 in its nanocomposite with phosphate glass. Journal of Polymer Science Part B: Polymer Physics, 2008. 46(9): p. 857-860.

17. Urman, K., T. Schweizer, and J.U. Otaigbe, Rheology of tin fluorophosphate glass/polyamide 12 hybrids in the low concentration regime. Journal of Rheology (1978-present), 2007. 51(6): p. 1171-1187.

18. Belyamani, I., J.U. Otaigbe, and W.R. Fielding, Development of new sustainable inorganic flame retardant additive system for polyamide 6, 6 with improved performance. Polymer Engineering \& Science, 2015. 55(8): p. 1741-1748.

19. Sanford, L.M. and P.A. Tick, Tin-phosphorus oxyfluoride glasses. 1982, Google Patents.

20. Beall, G.H., J.E. Dickinson Jr, and C.J. Quinn, Rare earth-containing zinc phosphate glasses. 1991, Google Patents.

21. Otaigbe, J.U. and G.H. Beall, Inorganic phosphate glasses as polymers. Trends in Polymer science, 1997. 5(11): p. 369-379.

22. Loong, C.-K., et al., Structure and dynamics of phosphate glasses: from ultra-to orthophosphate composition. Physica B: Condensed Matter, 1997. 241: p. 890-896.

23. Brow, R.K., Review: the structure of simple phosphate glasses. Journal of Non-Crystalline Solids, 2000. 263: p. 1-28.

24. Cho, J., A.R. Boccaccini, and M.S. Shaffer, Ceramic matrix composites containing carbon nanotubes. Journal of Materials Science, 2009. 44(8): p. 1934-1951.

25. Kotoul, M., et al., Toughening effects quantification in glass matrix composite reinforced by alumina platelets. Acta Materialia, 2008. 56(12): p. 2908-2918.

26. Boccaccini, A., et al., Assessment of damage induced by thermal shock in SiC-fiber-reinforced borosilicate glass composites. Composites science and technology, 1999. 59(1): p. 105-112.

27. Prewo, K.M. and J.J. Brennan, High-strength silicon carbide fibre-reinforced glass-matrix composites. Journal of Materials Science, 1980. 15(2): p. 463-468.

28. Cannillo, V., et al., Mechanical performance and fracture behaviour of glass-matrix composites reinforced with molybdenum particles. Composites science and technology, 2005. 65(7): p. 12761283.

29. Boccaccini, A., et al., Borosilicate glass matrix composites containing multi-wall carbon nanotubes. Journal of the European Ceramic Society, 2005. 25(9): p. 1515-1523.

30. Desimone, D., et al., Optically-transparent oxide fibre-reinforced glass matrix composites. Journal of Non-Crystalline Solids, 2010. 356(44): p. 2591-2597.

31. Lee, H., et al., Glass-ceramics and composites containing aluminum borate whiskers. Ceramics International, 2010. 36(5): p. 1589-1596.

32. Boccaccini, A., et al., Borosilicate and lead silicate glass matrix composites containing pyrochlore phases for nuclear waste encapsulation. Journal of nuclear materials, 2004. 327(2): p. 148-158.

33. Boccaccini, A.R., et al., Glass matrix composites from coal flyash and waste glass. Waste management, 1997. 17(1): p. 39-45.

34. Boccaccini, A.R., S. Atiq, and G. Helsch, Optomechanical glass matrix composites. Composites science and technology, 2003. 63(6): p. 779-783.

35. Thomas, B.J., M.S. Shaffer, and A.R. Boccaccini, Sol-gel route to carbon nanotube borosilicate glass composites. Composites Part A: Applied Science and Manufacturing, 2009. 40(6): p. 837845. 
36. Raab, D., et al., Mechanical properties of oxide-fiber reinforced glass matrix composites with $B N$ or SnO 2 interfaces. Materials Science and Engineering: A, 2006. 417(1): p. 341-347.

37. Boccaccini, A., et al., Processing and characterisation of model optomechanical composites in the system sapphire fibre/borosilicate glass matrix. Journal of materials processing technology, 2005. 169(2): p. 270-280.

38. Minay, E., V. Desbois, and A. Boccaccini, Innovative manufacturing technique for glass matrix composites: extrusion of recycled TV set screen glass reinforced with Al 203 platelets. Journal of materials processing technology, 2003. 142(2): p. 471-478.

39. Boccaccini, A., et al., Effect of thermomechanical loads on microstructural damage and on the resulting thermomechanical behaviour of silicon carbide fibre-reinforced glass matrix composites. Materials characterization, 2005. 54(1): p. 75-83.

40. Giannelis, E., R. Krishnamoorti, and E. Manias, Polymer-silicate nanocomposites: model systems for confined polymers and polymer brushes, in Polymers in confined environments. 1999, Springer. p. 107-147.

41. Paul, D. and C. Bucknall, Polymer blends: formulation and performance. Canada: John Wiley \& Sons, 2000: p. 1224.

42. Gnanasekaran, D., K. Madhavan, and B. Reddy, Developments of polyhedral oligomeric silsesquioxanes (POSS), POSS nanocomposites and their applications: a review. J Sci Ind Res, 2009. 68(6): p. 437-64.

43. Wang, W., Y.-I. Guo, and J.U. Otaigbe, The synthesis, characterization and biocompatibility of poly (ester urethane)/polyhedral oligomeric silesquioxane nanocomposites. Polymer, 2009. 50(24): p. 5749-5757.

44. Kuo, S.-W. and F.-C. Chang, POSS related polymer nanocomposites. Progress in Polymer Science, 2011. 36(12): p. 1649-1696.

45. Phillips, S.H., T.S. Haddad, and S.J. Tomczak, Developments in nanoscience: polyhedral oligomeric silsesquioxane (POSS)-polymers. Current Opinion in Solid State and Materials Science, 2004. 8(1): p. 21-29.

46. Nanda, A.K., et al., Nanostructured polyurethane/POSS hybrid aqueous dispersions prepared by homogeneous solution polymerization. Macromolecules, 2006. 39(20): p. 7037-7043.

47. Lichtenhan, J.D., Y.A. Otonari, and M.J. Carr, Linear hybrid polymer building blocks: methacrylate-functionalized polyhedral oligomeric silsesquioxane monomers and polymers. Macromolecules, 1995. 28(24): p. 8435-8437.

48. Zheng, L., R.J. Farris, and E.B. Coughlin, Novel polyolefin nanocomposites: synthesis and characterizations of metallocene-catalyzed polyolefin polyhedral oligomeric silsesquioxane copolymers. Macromolecules, 2001. 34(23): p. 8034-8039.

49. Gonzalez, R.I., S.H. Phillips, and G.B. Hoflund, In situ oxygen-atom erosion study of polyhedral oligomeric silsesquioxane-siloxane copolymer. Journal of Spacecraft and Rockets, 2000. 37(4): p. 463-467.

50. Baldi, F., et al., Mechanical characterization of polyhedral oligomeric silsesquioxane/polypropylene blends. Journal of applied polymer science, 2007. 105(2): p. 935943.

51. Zhao, Y. and D.A. Schiraldi, Thermal and mechanical properties of polyhedral oligomeric silsesquioxane (POSS)/polycarbonate composites. Polymer, 2005. 46(25): p. 11640-11647.

52. Yoon, K.H., et al., Properties of poly (ethylene terephthalate) containing epoxy-functionalized polyhedral oligomeric silsesquioxane. Polymer international, 2005. 54(1): p. 47-53.

53. $\mathrm{Xu}, \mathrm{H}$., et al., Preparation, Thermal Properties, and $\mathrm{Tg}$ Increase Mechanism of Poly (acetoxystyrene-co-octavinyl-polyhedral oligomeric silsesquioxane) Hybrid Nanocomposites. Macromolecules, 2005. 38(25): p. 10455-10460. 
54. Li, G.Z., et al., Synthesis and properties of poly (isobutyl methacrylate-co-butanediol dimethacrylate-co-methacryl polyhedral oligomeric silsesquioxane) nanocomposites. Journal of Polymer Science Part A: Polymer Chemistry, 2005. 43(2): p. 355-372.

55. Huang, C.-F., et al., Influence of PMMA-chain-end tethered polyhedral oligomeric silsesquioxanes on the miscibility and specific interaction with phenolic blends. Macromolecules, 2006. 39(1): p. 300-308.

56. Hany, R., et al., Chemical synthesis and characterization of POSS-functionalized poly [3hydroxyalkanoates]. Polymer, 2005. 46(14): p. 5025-5031.

57. Dokukin, M.E. and I. Sokolov, Quantitative mapping of the elastic modulus of soft materials with HarmoniX and PeakForce QNM AFM modes. Langmuir, 2012. 28(46): p. 16060-16071.

58. Lorenzoni, M., et al., Nanomechanical properties of solvent cast polystyrene and poly (methyl methacrylate) polymer blends and self-assembled block copolymers. Journal of Micro/Nanolithography, MEMS, and MOEMS, 2015. 14(3): p. 033509-033509.

59. Cappella, B. and G. Dietler, Force-distance curves by atomic force microscopy. Surface science reports, 1999. 34(1): p. 1-104.

60. Massiot, D., et al., Modelling one-and two-dimensional solid-state NMR spectra. Magnetic Resonance in Chemistry, 2002. 40(1): p. 70-76.

61. Kannan, A.G., N.R. Choudhury, and N.K. Dutta, Synthesis and characterization of methacrylate phospho-silicate hybrid for thin film applications. Polymer, 2007. 48(24): p. 7078-7086.

62. Borisov, S., Organosilicon derivatives of Phosphorus and Sulfur. 2012: Springer Science \& Business Media.

63. Fang, Y., et al., Tin fluorophosphate nonwovens by melt state centrifugal Forcespinning. Journal of Materials Science, 2014. 49(24): p. 8252-8260.

64. Bartholomew, R.F., Structure and properties of silver phosphate glasses-Infrared and visible spectra. Journal of Non-Crystalline Solids, 1972. 7(3): p. 221-235.

65. Bunker, B., G. Arnold, and J.A. Wilder, Phosphate glass dissolution in aqueous solutions. Journal of Non-Crystalline Solids, 1984. 64(3): p. 291-316.

66. Ding, J., et al., The properties and structure of $S n \quad C a \quad P \quad O \quad F$ glasses. Materials chemistry and physics, 2003. 82(1): p. 61-67.

67. Sun, K. and W.M. Risen, Rare earth phosphate glasses. Solid state communications, 1986. 60(9): p. 697-700.

68. Liang, K., et al., Cyanate ester/polyhedral oligomeric silsesquioxane (POSS) nanocomposites: synthesis and characterization. Chemistry of materials, 2006. 18(2): p. 301-312.

69. Anma, M., et al., Structure of glasses in the system $S n \quad P b \quad P \quad F \quad O$. Journal of NonCrystalline Solids, 1991. 135(1): p. 79-85.

70. Brow, R.K., et al., An x-ray photoelectron spectroscopy study of anion bonidng in tin (II) fluorophosphate glass. Physics and chemistry of glasses, 1992. 33(2): p. 33-39.

71. Wagner, T., et al., 10th International Conference on Solid State Chemistry, Pardubice, Czech RepublicStructure of SnF2-SnO-P2O5 Glasses. Physics Procedia, 2013. 44: p. 159-165.

72. York-Winegar, J., et al., Structure of SnF2-SnO-P2O5 Glasses. Physics Procedia, 2013. 44: p. 159165.

73. Brow, R.K., R.J. Kirkpatrick, and G.L. Turner, Nature of alumina in phosphate glass: II, structure of sodium alurninophosphate glass. Journal of the American Ceramic Society, 1993. 76(4): p. 919928.

74. Onyiriuka, E., Zinc phosphate glass surfaces studied by XPS. Journal of non-crystalline solids, 1993. 163(3): p. 268-273.

75. Brow, R.K., M.R. Reidmeyer, and D.E. Day, Oxygen bonding in nitrided sodium- and lithiummetaphosphate glasses. Journal of Non-Crystalline Solids, 1988. 99(1): p. 178-189. 
76. Brow, R.K., An XPS study of oxygen bonding in zinc phosphate and zinc borophosphate glasses. Journal of non-crystalline solids, 1996. 194(3): p. 267-273.

77. Mekki, A., D. Holland, and C. McConville, X-ray photoelectron spectroscopy study of copper sodium silicate glass surfaces. Journal of non-crystalline solids, 1997. 215(2): p. 271-282.

78. Zhang, L., C.C. de Araujo, and H. Eckert, A new sol-gel route to aluminum fluoride phosphate glasses: Mechanistic investigations by NMR spectroscopy. Chemistry of materials, 2005. 17(12): p. 3101-3107.

79. Bräuniger, T., S. Ghedia, and M. Jansen, Covalent Bonds in $\alpha$-SnF2 Monitored by J-Couplings in Solid-State NMR Spectra. Zeitschrift für anorganische und allgemeine Chemie, 2010. 636(13-14): p. 2399-2404.

80. Haubenreisser, U., U. Sternberg, and A.-R. Grimmer, High-field 31P NMR investigations of the chemical shielding and indirect dipolar coupling of polycrystalline fluorophosphates. Molecular Physics, 1987. 60(1): p. 151-163.

81. Brow, R.K., Z. Osborne, and R.J. Kirkpatrick, A multinuclear MAS NMR study of the short-range structure of fluorophosphate glass. Journal of materials research, 1992. 7(07): p. 1892-1899.

82. Holland, D., et al., Lone-pair effects and structural trends in $x$ SnO-(1-x) P2O5 glasses deduced from 31P and 119Sn nuclear magnetic resonance. Journal of Physics: Condensed Matter, 2002. 14(49): p. 13609.

83. Bekaert, É., et al., Structure and properties of $x$ SnO-(100-x) P 205 glasses. Comptes Rendus Chimie, 2004. 7(3): p. 377-382.

84. Tischendorf, B.C., et al., Investigation of structure and morphology dynamics in tin fluorophosphate glass-polyethylene hybrids using solid-state $1 \mathrm{H}, 13 \mathrm{C}$, and 31P MAS NMR. Chemistry of materials, 2002. 14(1): p. 341-347.

85. Cody, G.D., et al., Silicate-phosphate interactions in silicate glasses and melts: I. A multinuclear (27 Al, 29 Si, 31 P) MAS NMR and ab initio chemical shielding (31 P) study of phosphorous speciation in silicate glasses. Geochimica et Cosmochimica Acta, 2001. 65(14): p. 2395-2411.

86. Tian, J., W. Yu, and C. Zhou, The preparation and rheology characterization of long chain branching polypropylene. Polymer, 2006. 47(23): p. 7962-7969.

87. Wu, D., L. Wu, and M. Zhang, Rheology of multi-walled carbon nanotube/poly (butylene terephthalate) composites. Journal of Polymer Science Part B: Polymer Physics, 2007. 45(16): p. 2239-2251.

88. Rouse Jr, P.E., A theory of the linear viscoelastic properties of dilute solutions of coiling polymers. The Journal of Chemical Physics, 1953. 21(7): p. 1272-1280.

89. Ferry, J.D., Viscoelastic properties of polymers. 1980: John Wiley \& Sons.

90. Sammler, R., et al., Melt rheology of zinc alkali phosphate glasses. Journal of Rheology (1978present), 1996. 40(2): p. 285-302.

91. Adalja, S.B. and J.U. Otaigbe, Melt rheology of tin phosphate glasses. Appl Rheol, 2001. 11(1): p. 10-18.

92. Yang, C.-W., Y.-H. Lu, and S. Hwang, Imaging surface nanobubbles at graphite-water interfaces with different atomic force microscopy modes. Journal of Physics: Condensed Matter, 2013. 25(18): p. 184010.

93. Derjaguin, B.V., V.M. Muller, and Y.P. Toporov, Effect of contact deformations on the adhesion of particles. Journal of Colloid and interface science, 1975. 53(2): p. 314-326. 
Figures

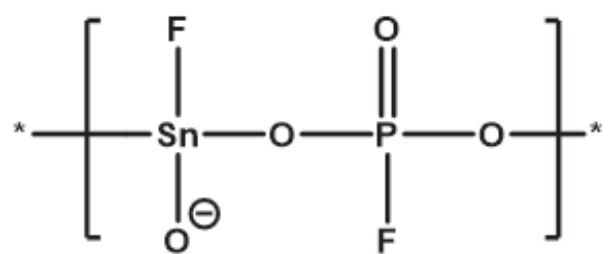

(a)

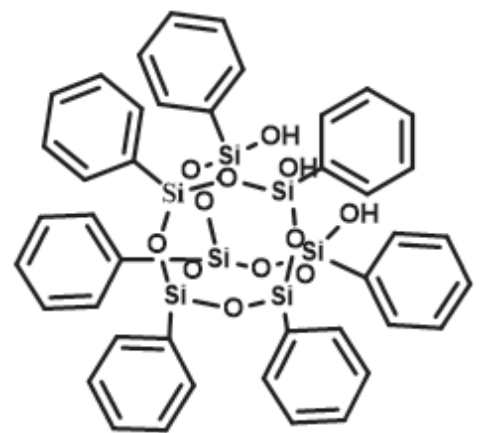

(b)

Fig. 1. Structure of (a) Pglass and (b) TSP POSS 


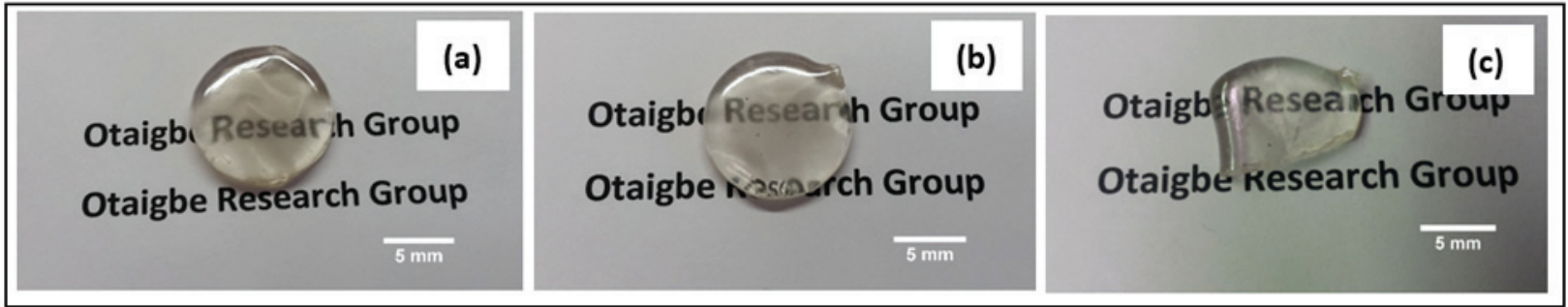

Fig. 2. Comparison of synthesized Pglass matrix nanocomposites incorporating TSP-POSS prepared by the synthesis method described in the text; (a) neat Pglass, (b) 5 wt.\% TSP-POSS, (c) 10 wt.\% TSP-POSS. 

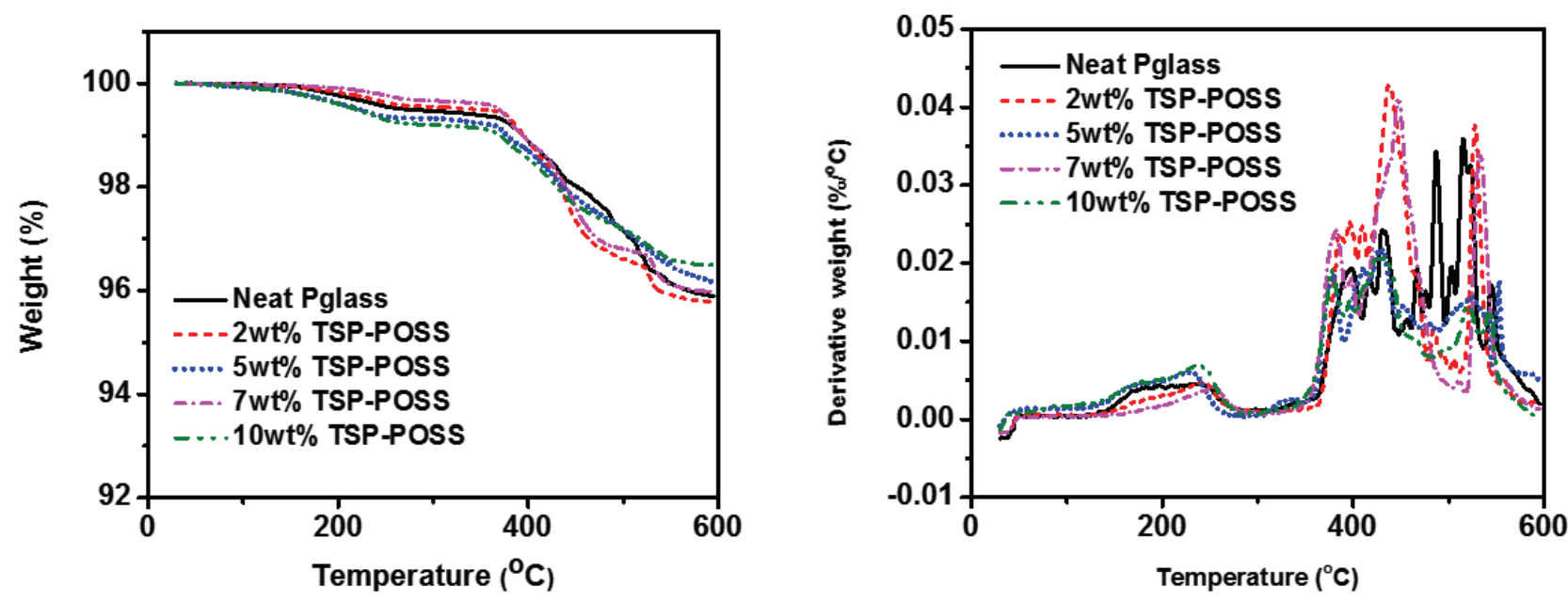

Fig. 3. TGA curves for the neat Pglass and its nanocomposites containing POSS concentrations indicated, recorded at $10^{\circ} \mathrm{C} / \mathrm{min}$ in $\mathrm{N}_{2}$ gas atmosphere. 


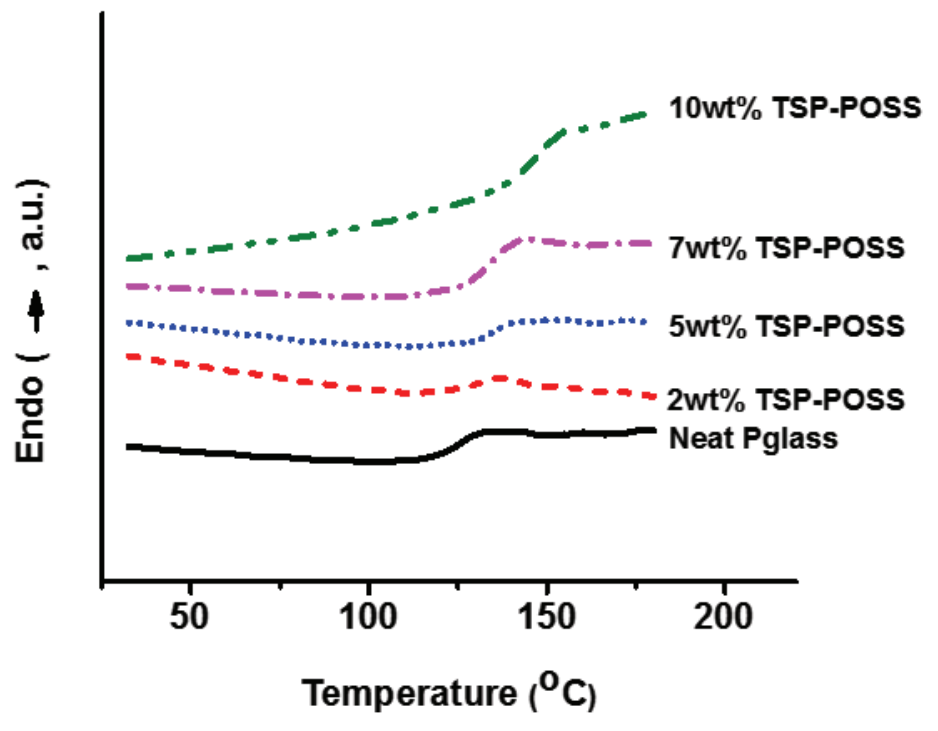

Fig. 4. DSC scan $\left(10^{\circ} \mathrm{C} / \mathrm{min}\right)$ for neat Pglass and nanocomposites containing the POSS concentrations indicated. 


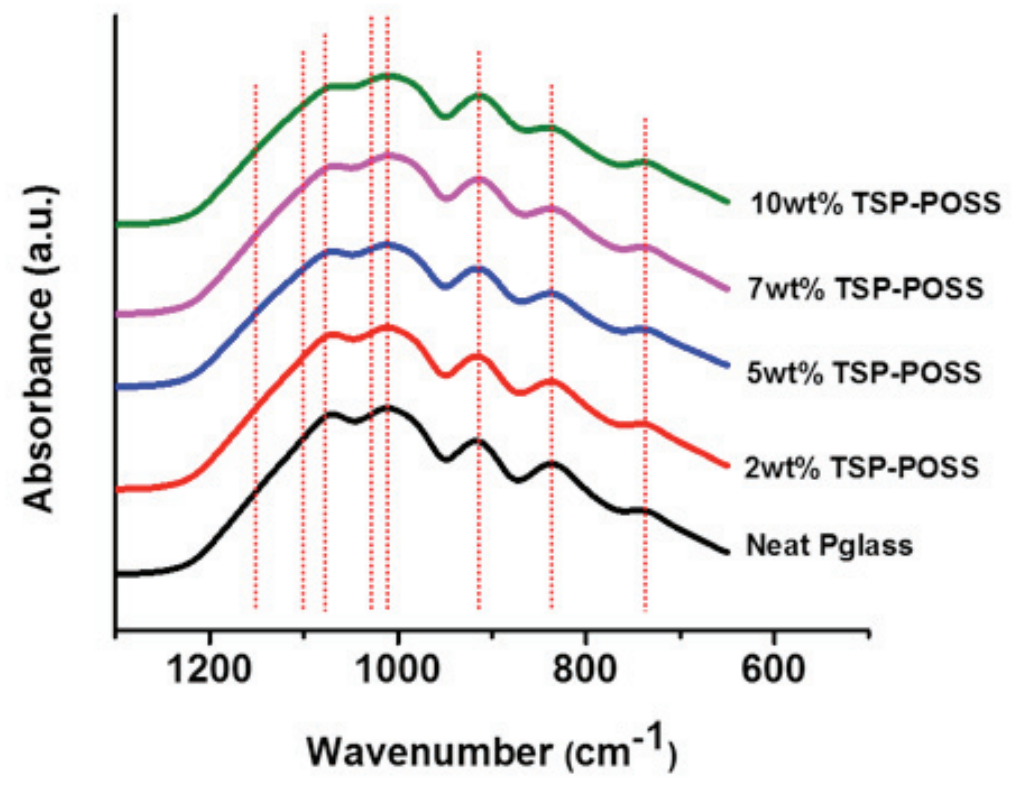

Fig. 5. ATR-FTIR spectra of neat Pglass and nanocomposites incorporating various amount of TSP-POSS. The broken lines are guides to the peak values. 

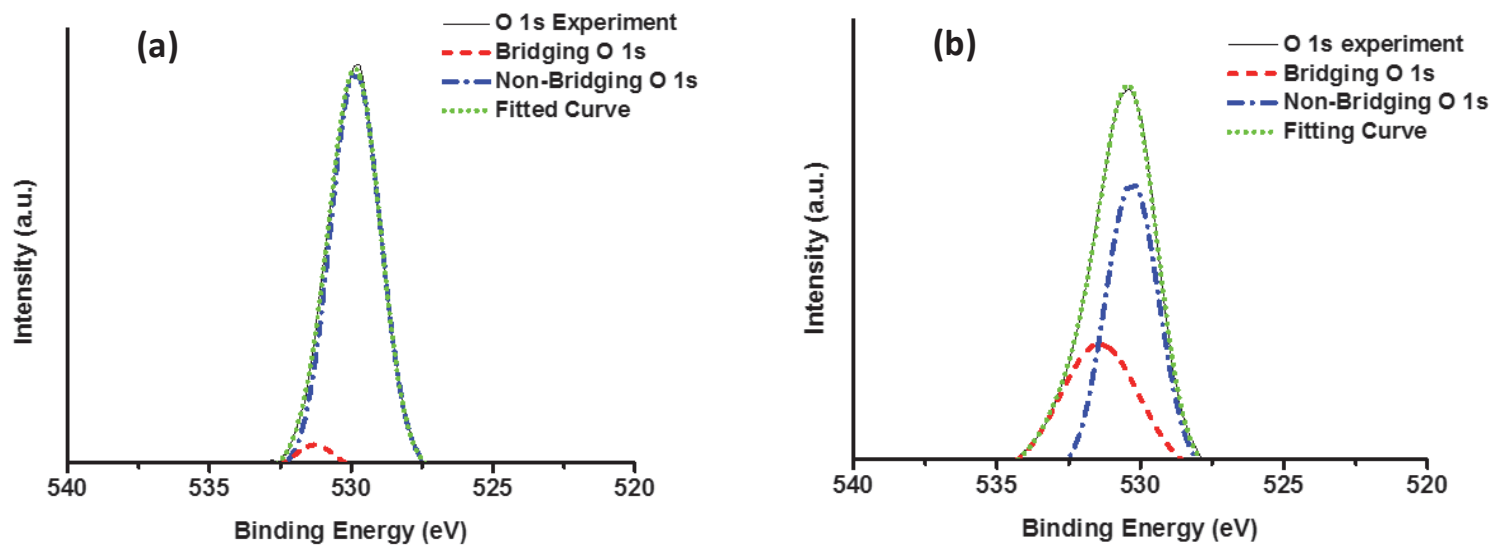

Fig. 6. XPS spectra of (a) neat Pglass and (b) nanocomposite incorporating 5 wt.\% TSP-POSS 

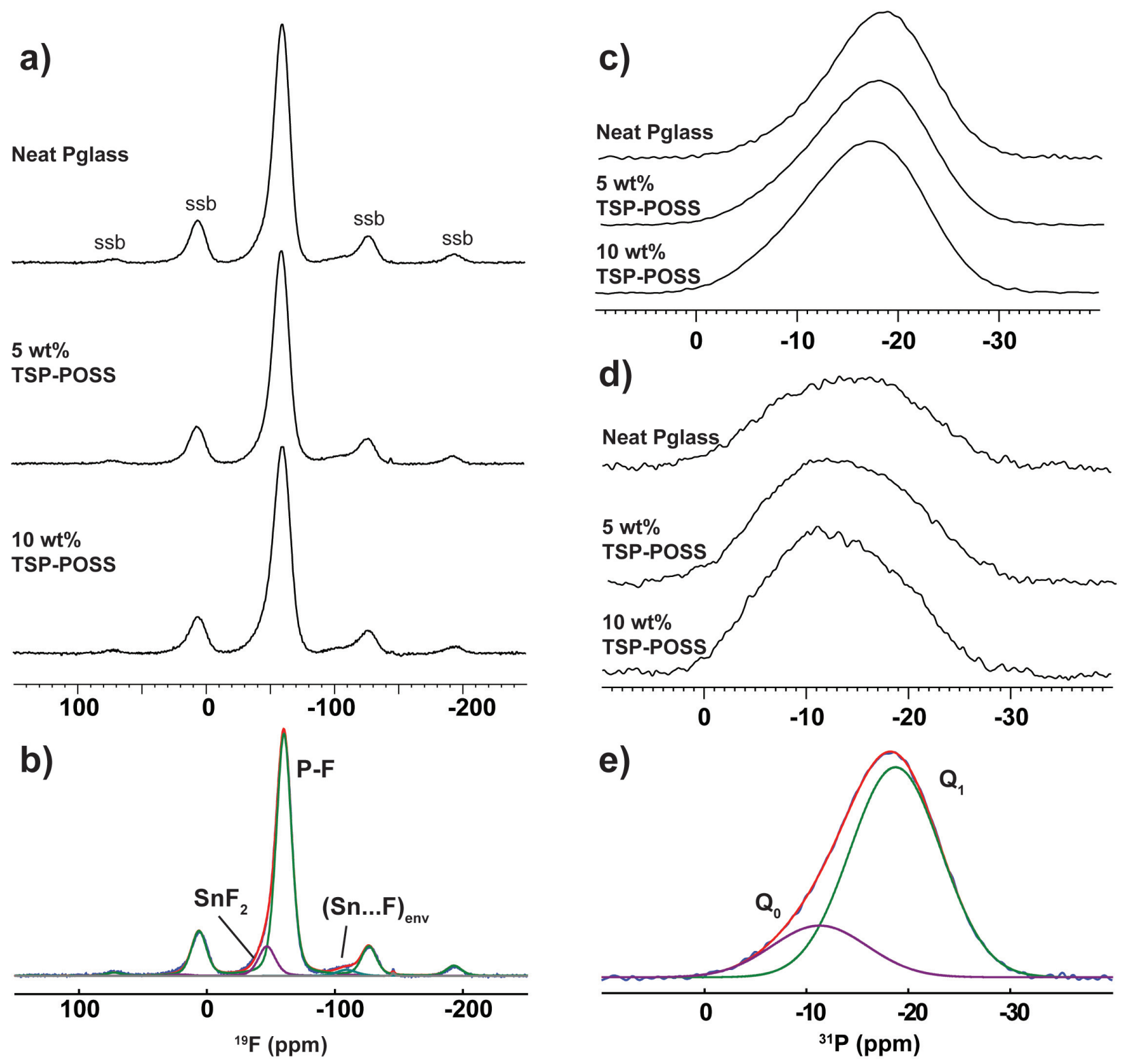

Fig. 7. (a) ${ }^{19}$ F DP MAS NMR spectra, (b) deconvolution showing the different F environment, (c) ${ }^{31} \mathrm{P}$ DP MAS NMR spectra and (d) ${ }^{1} \mathrm{H}-{ }^{31} \mathrm{P}$ CPMAS NMR spectra of nanocomposites prepared by synthesis method, along with the (e) deconvolution of the TFP glass spectra into assigned $\mathrm{Q}^{0}$ and $\mathrm{Q}^{1}$ phosphate environments (ssb = spinning side bands). 


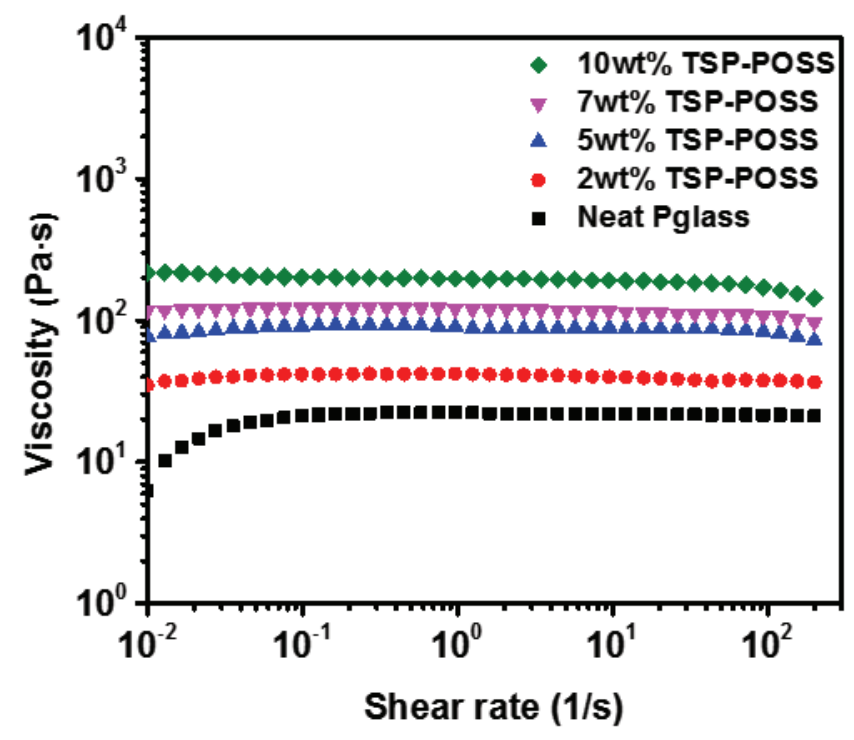

Fig. 8. Variation of viscosity versus shear rate for the neat Pglass and nanocomposites. 

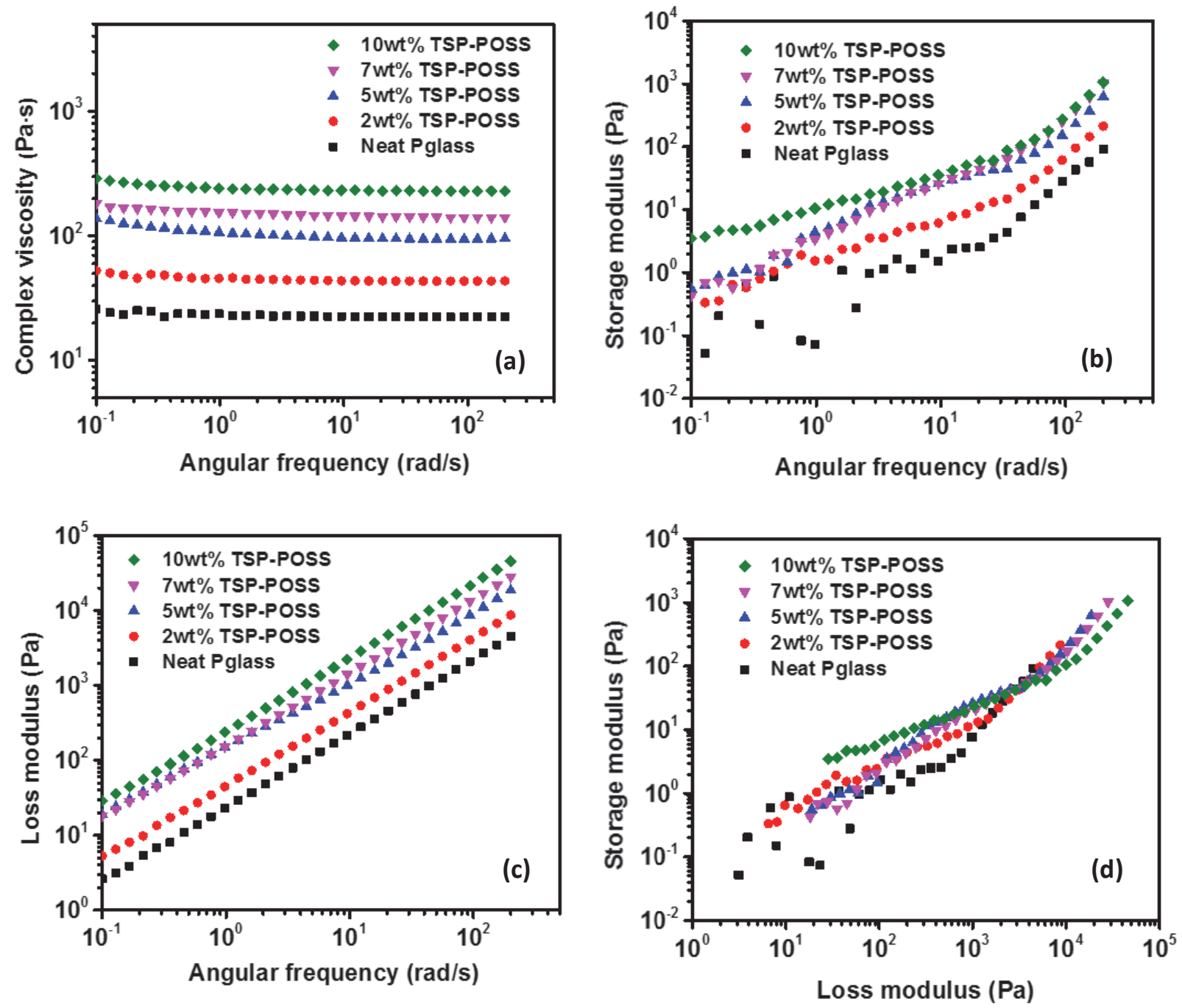

Fig. 9. Frequency dependencies of (a) complex viscosity, (b) storage modulus and (c) loss modulus for neat Pglass and nanocomposites incorporating TSP-POSS. (d) Han plot for neat Pglass and nanocomposites incorporating TSP-POSS. 


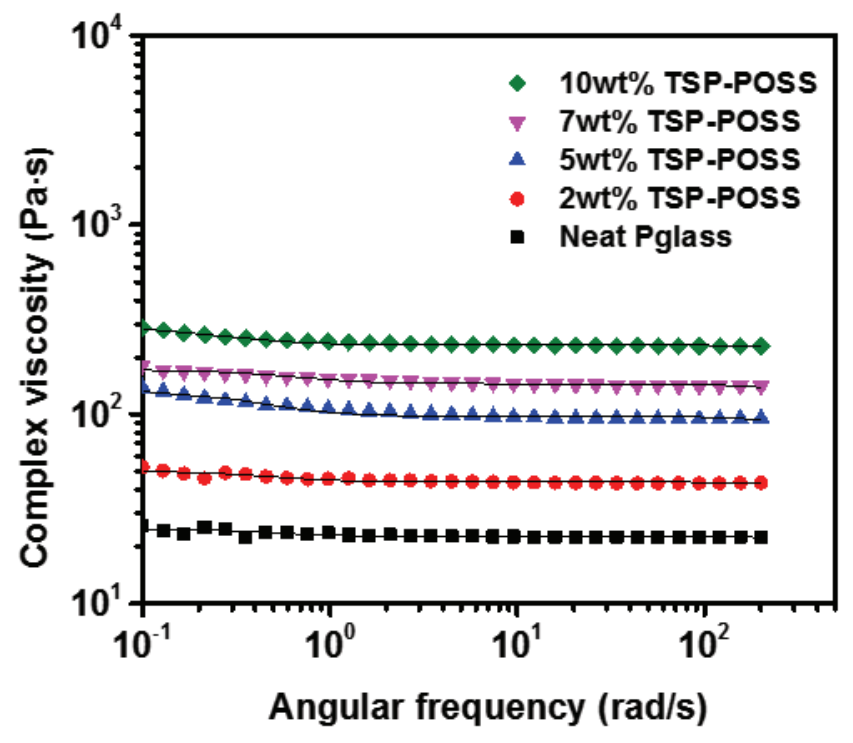

Fig. 10. Two-parameter Rouse fit (lines) of the complex viscosity data (symbols) as a function of frequency for the neat Pglass and nanocomposites incorporating TSP-POSS. 

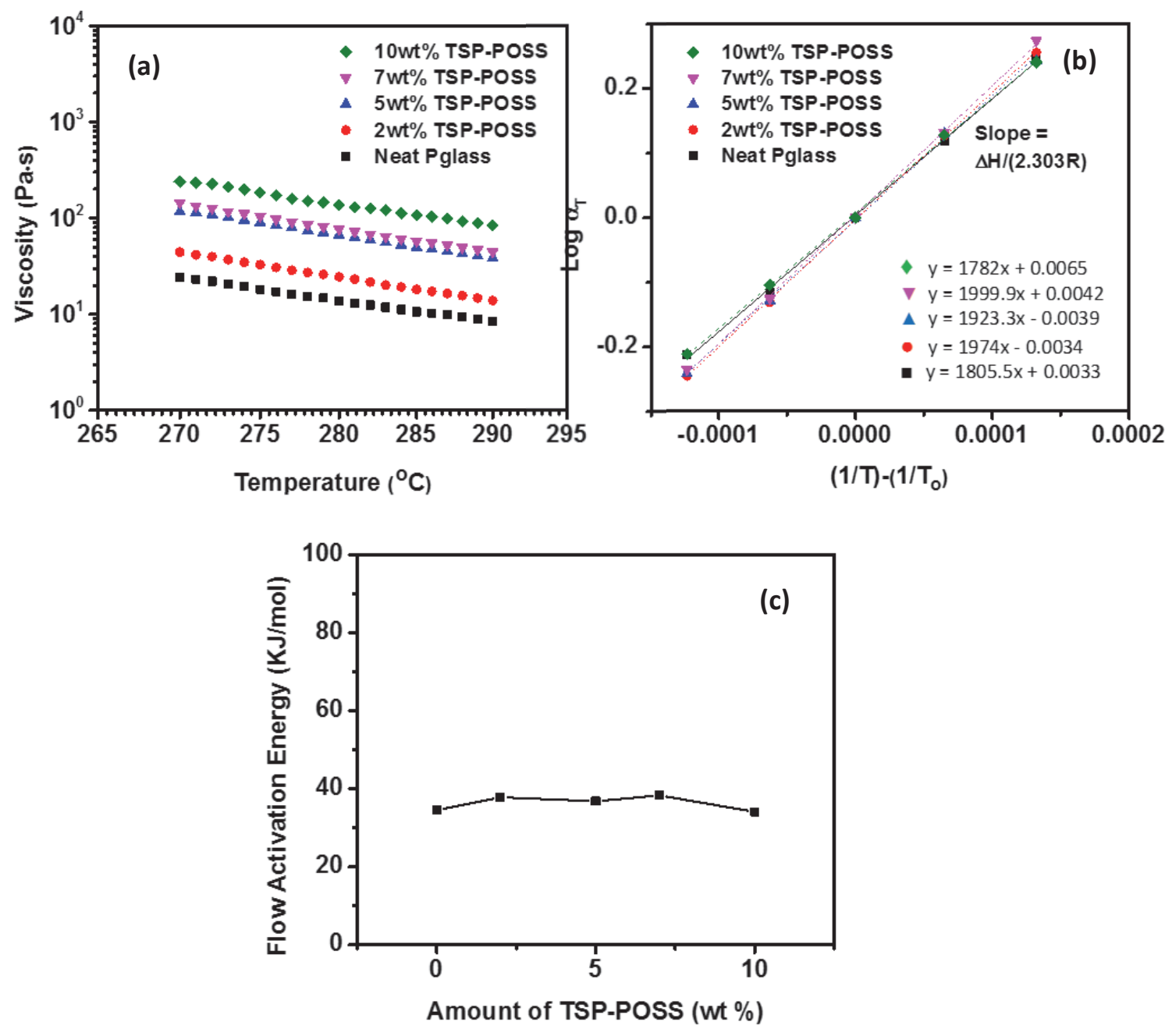

Fig. 11. (a) Temperature dependency of viscosity at a shear rate of $5 \mathrm{~s}^{-1}$, (b) fitted graphs of equations for flow activation energy calculation described in the text, and (c) calculated flow activation energy of neat Pglass and nanocomposites incorporating TSP-POSS described in the text. 

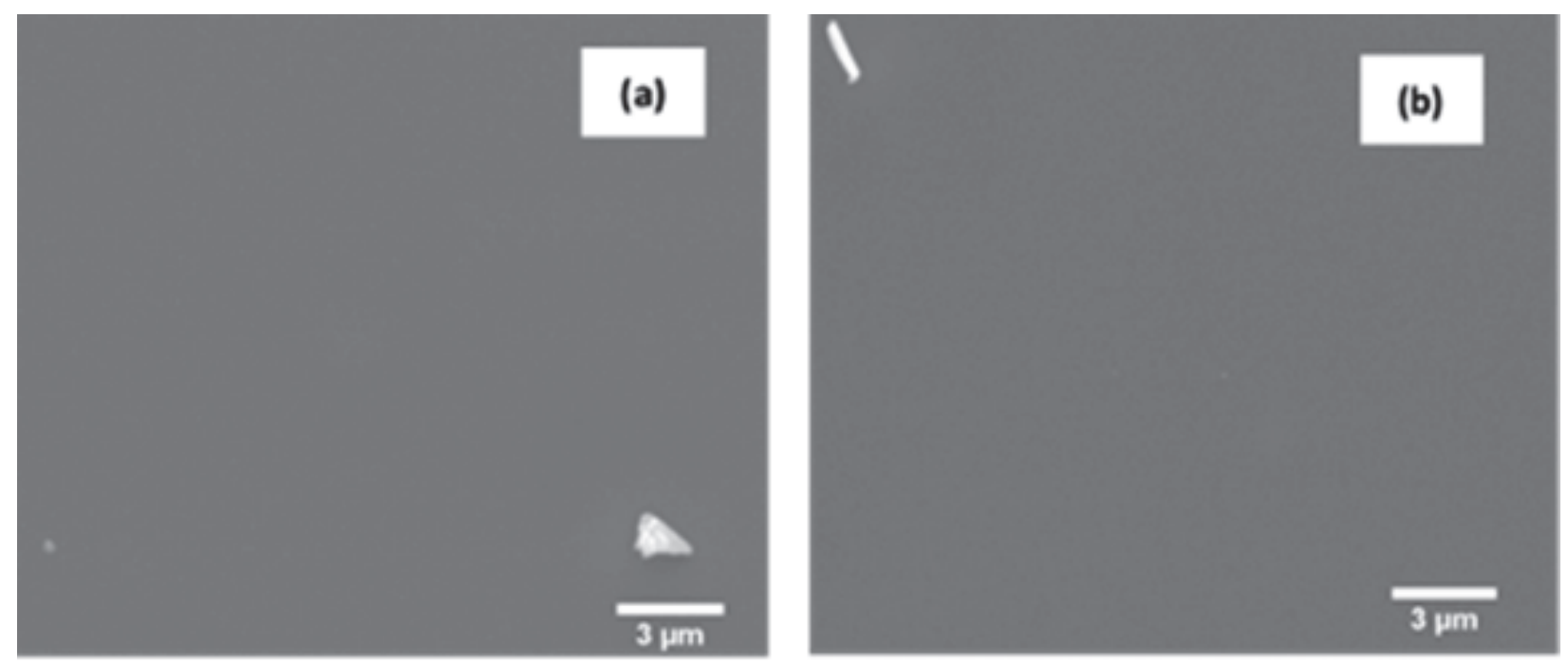

Fig. 12. SEM images of fracture surface of (a) the neat Pglass and (b) Pglass matrix nanocomposites incorporating $10 \mathrm{wt}$ \% TSP-POSS prepared by synthesis method. 

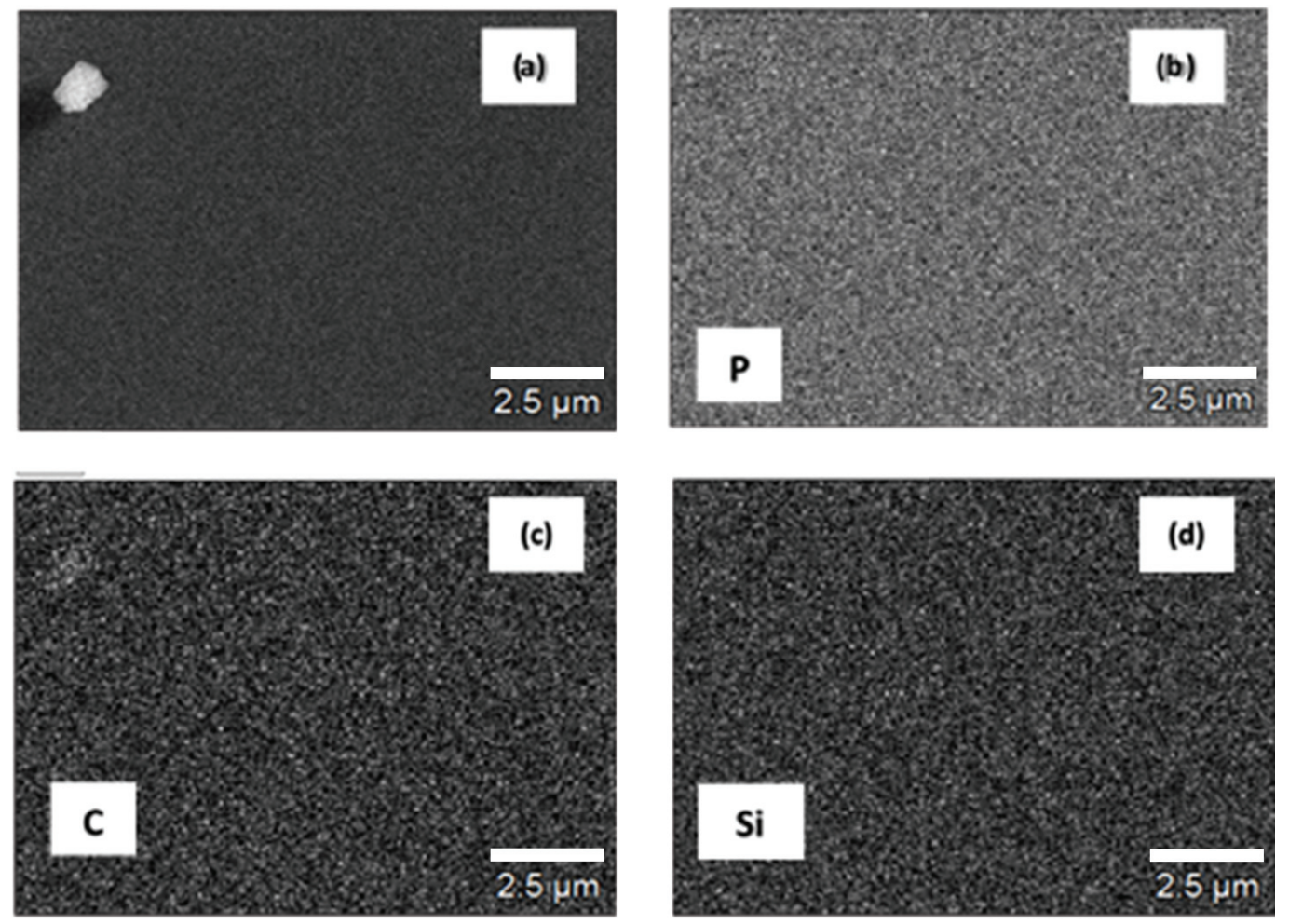

Fig. 13. (a) SEM image and SEM-EDX mapping images of each element (b) $P$, phosphorous; (c) C, carbon; (d) $\mathrm{Si}$, silicon on the fracture surface of the Pglass matrix nanocomposites incorporating $10 \mathrm{wt}$ \% TSP-POSS prepared by synthesis method (black background and white spot for each element) 

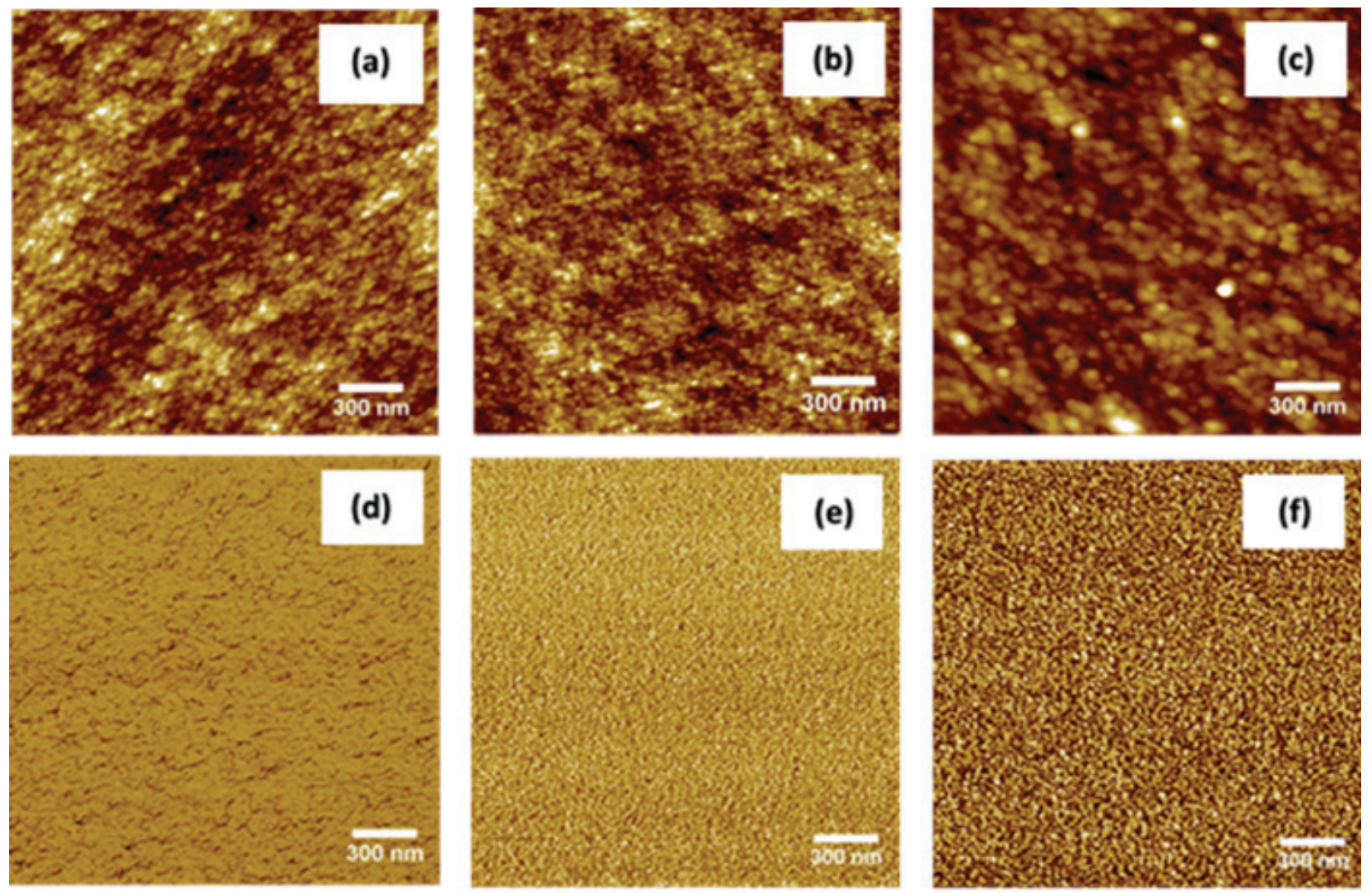

Fig. 14. AFM height images $(2 \mu \mathrm{m} \times 2 \mu \mathrm{m})$ on the fracture surface of (a) the neat Pglass, (b) $5 \mathrm{wt} \%$ TSP-POSS and (c) 10 wt.\% TSP-POSS incorporated Pglass matrix nanocomposites; AFM phase images of (d) the neat Pglass, (e) 5 wt.\% TSP-POSS and (f) 10 wt.\% TSP-POSS incorporated in the Pglass matrix nanocomposites. 

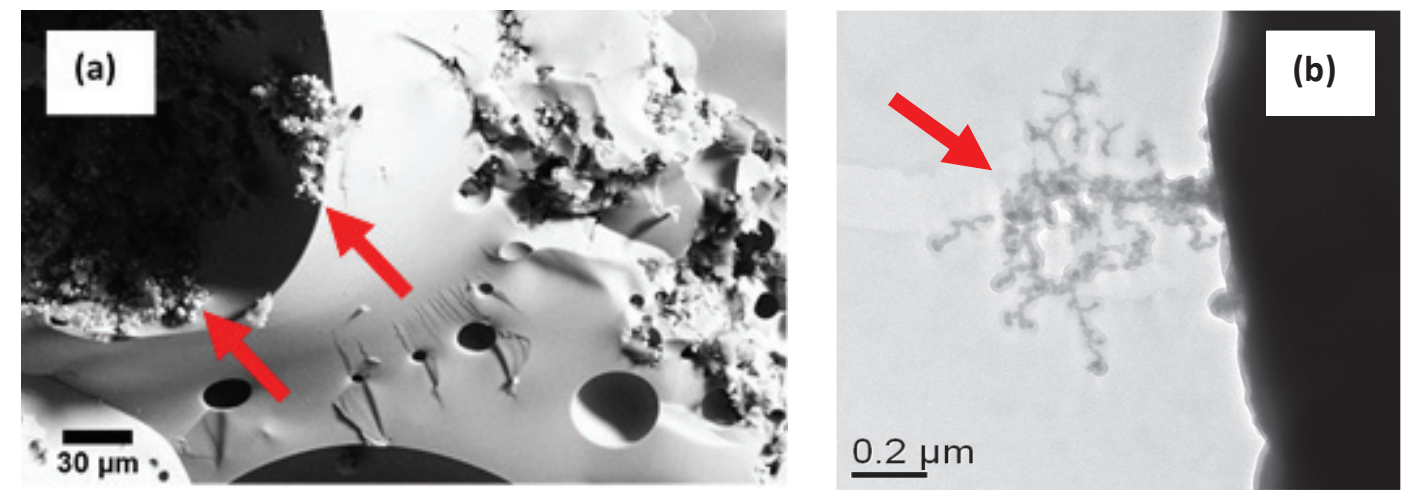

Fig. 15. (a) SEM image of the physically blended 5 wt.\% POSS/Pglass sample showing POSS aggregation (arrows) and (b) TEM image of attached POSS on the surface of heterogeneous POSS/Pglass physically blended 5 wt. \% POSS/Pglass sample. 

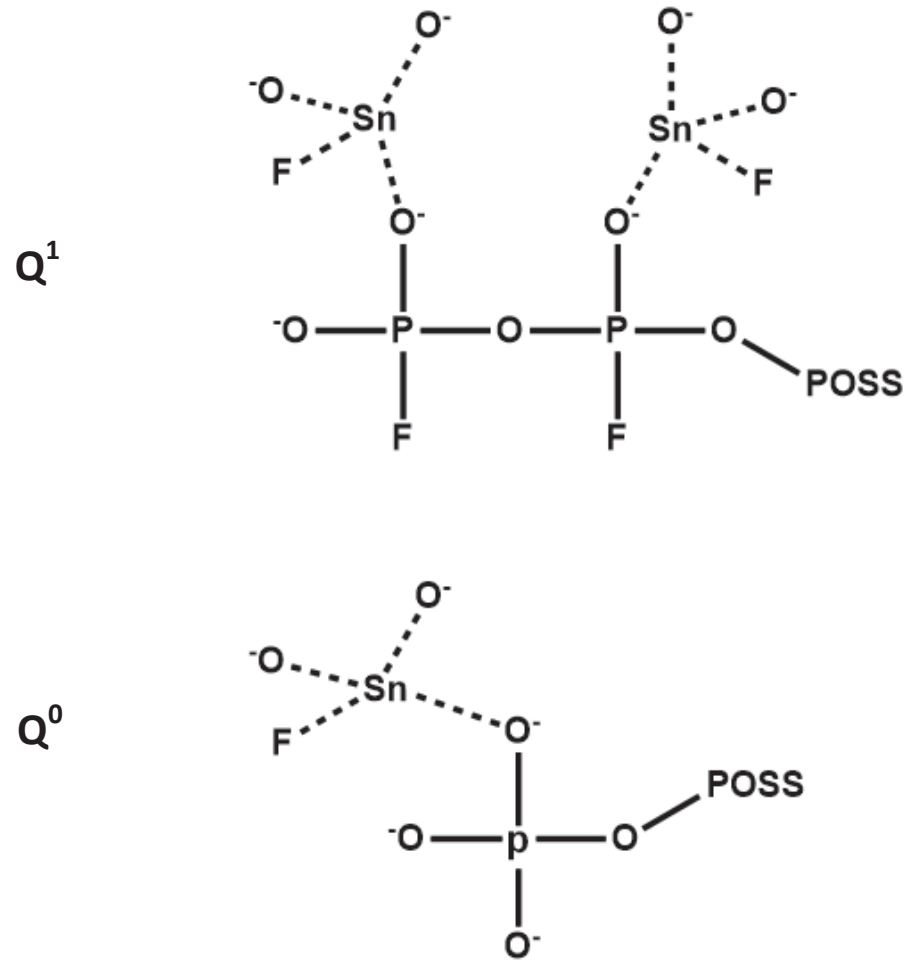

Fig. 16. The plausible structure of Pglass/TSP-POSS nanocomposites prepared by the synthesis method described in the text (see Fig. $1 \mathrm{~b}$ for the chemical structure of POSS). 

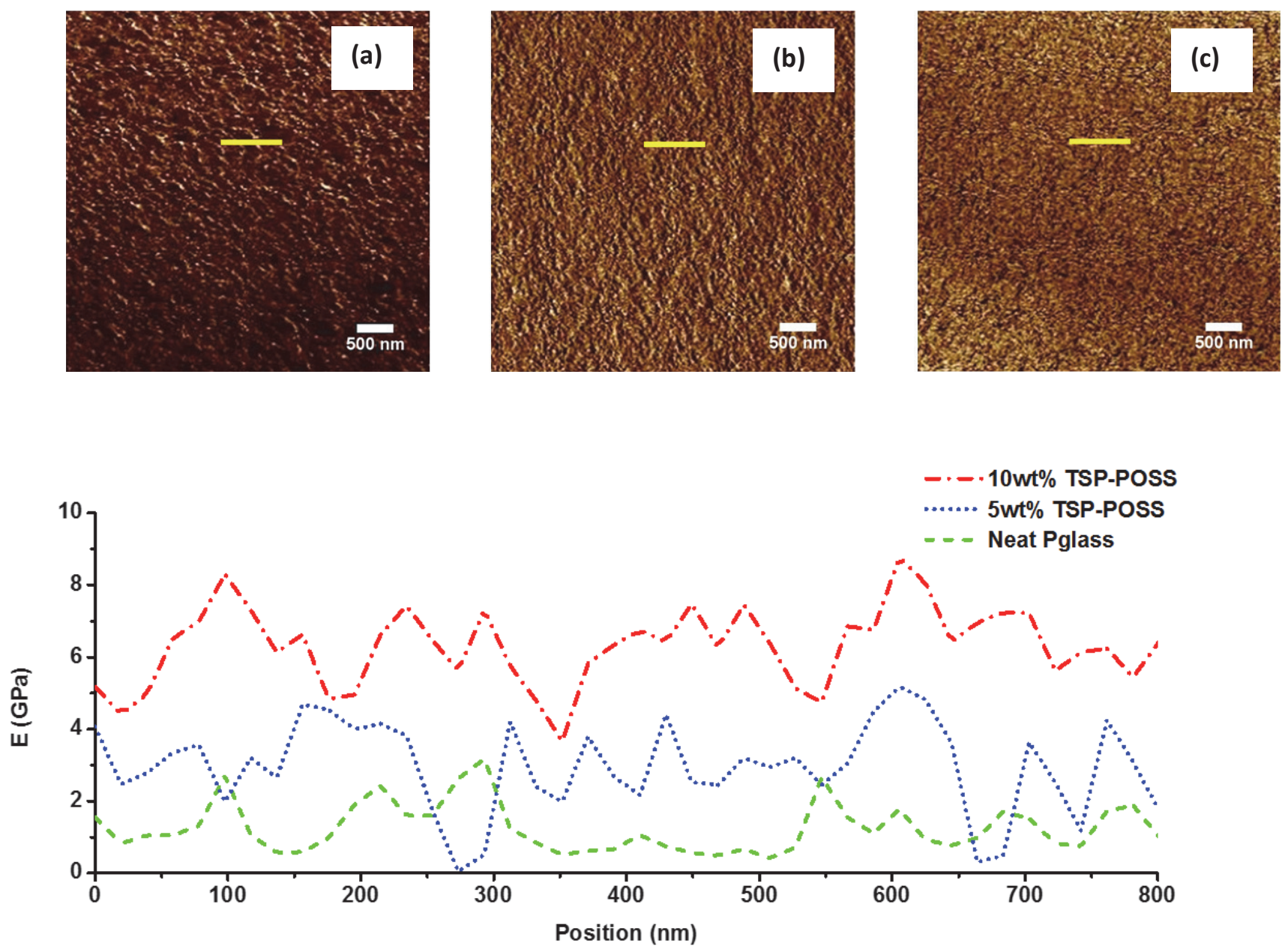

Fig. 17. Modulus images of (a) neat Pglass (b) 5 wt.\% TSP-POSS (c) 10 wt.\% TSP-POSS and (d) modulus values along profile on each image described in the text. 


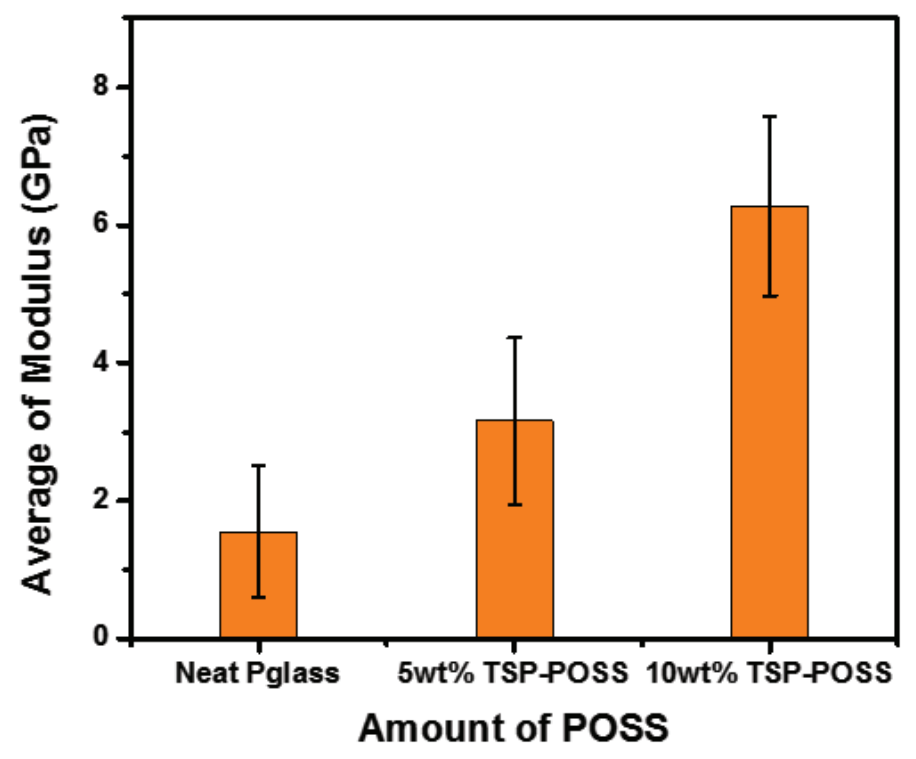

Fig. 18. Average and standard deviation of modulus with five-profile measurements on each sample. 


\section{Tables}

Table 1. The deconvolution of ${ }^{31} \mathrm{P}$ DP MAS NMR data on nanocomposites prepared by synthesis method.

\begin{tabular}{|c|c|c|c|}
\hline & Neat Pglass (\%) & 5 wt.\% TSP-POSS (\%) & 10 wt.\% TSP-POSS (\%) \\
\hline $\mathrm{Q}^{0}$ & $20.5 \pm 1$ & $25.7 \pm 1$ & $27.1 \pm 1$ \\
\hline $\mathrm{Q}^{1}$ & $79.5 \pm 1$ & $74.3 \pm 1$ & $72.9 \pm 1$ \\
\hline
\end{tabular}

Table 2. Fit parameters obtained from the 2-parameter Rouse model used for prediction of the complex viscosity as a function of the frequency

\begin{tabular}{|c|c|c|c|c|}
\hline & $\eta_{1}$ & $\tau_{1}$ & $\eta_{2}$ & $\tau_{2}$ \\
\hline Neat Pglass & 2.33 & -2.32 & 22.63 & -0.00076 \\
\hline 2 wt.\% TSP-POSS & 6.66 & 2.44 & 43.89 & -0.00095 \\
\hline 5 wt.\% TSP-POSS & 36.86 & 2.81 & 97.62 & 0.0016 \\
\hline 7 wt.\% TSP-POSS & 27.14 & 1.72 & 144.92 & -0.0015 \\
\hline 10 wt.\% TSP-POSS & 56.86 & 4.28 & 233.23 & -0.0012 \\
\hline
\end{tabular}




\section{Graphical abstract}
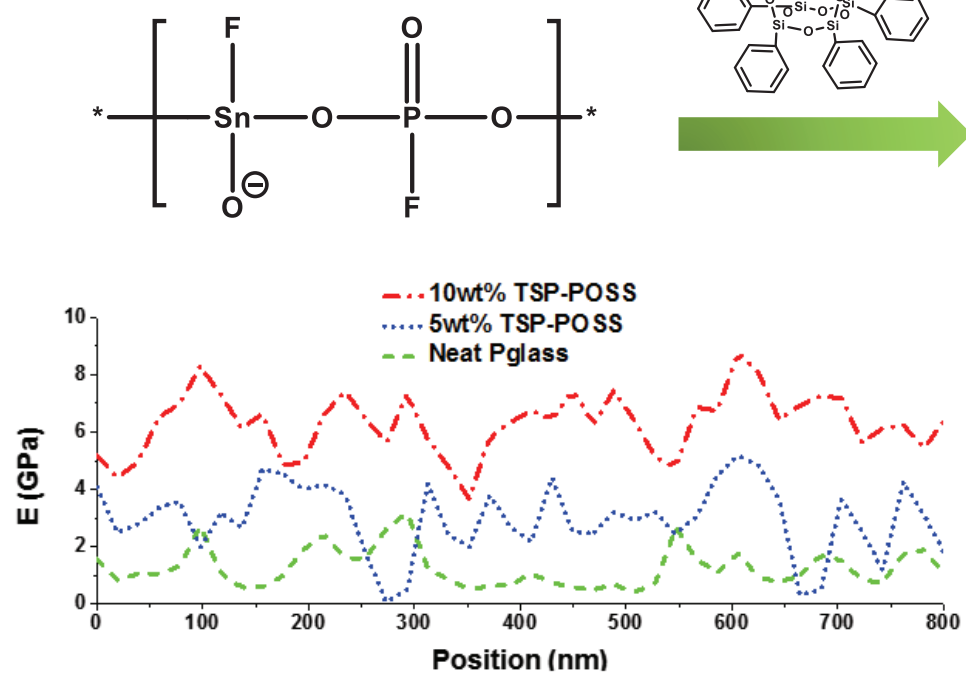
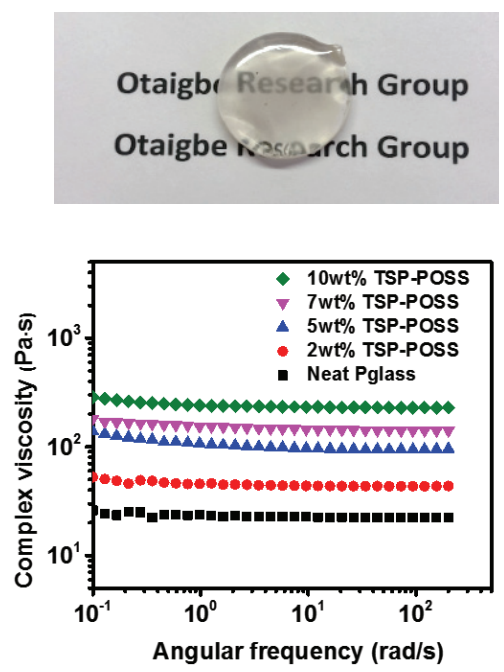